\title{
Optimization under uncertainty of a biomass-integrated renewable energy microgrid with energy storage
}

\author{
Zheng, Yingying; Jenkins, Bryan M.; Kornbluth, Kurt; Træholt, Chresten
}

Published in:

Renewable Energy

Link to article, DOI:

10.1016/j.renene.2018.01.120

Publication date:

2018

Document Version

Peer reviewed version

Link back to DTU Orbit

Citation (APA):

Zheng, Y., Jenkins, B. M., Kornbluth, K., \& Træholt, C. (2018). Optimization under uncertainty of a biomassintegrated renewable energy microgrid with energy storage. Renewable Energy, 123, 204-217.

https://doi.org/10.1016/j.renene.2018.01.120

\section{General rights}

Copyright and moral rights for the publications made accessible in the public portal are retained by the authors and/or other copyright owners and it is a condition of accessing publications that users recognise and abide by the legal requirements associated with these rights.

- Users may download and print one copy of any publication from the public portal for the purpose of private study or research.

- You may not further distribute the material or use it for any profit-making activity or commercial gain

- You may freely distribute the URL identifying the publication in the public portal 


\section{Accepted Manuscript}

Optimization under Uncertainty of a Biomass-Integrated Renewable Energy Microgrid with Energy Storage

Yingying Zheng, Bryan M. Jenkins, Kurt Kornbluth, Chresten Træholt

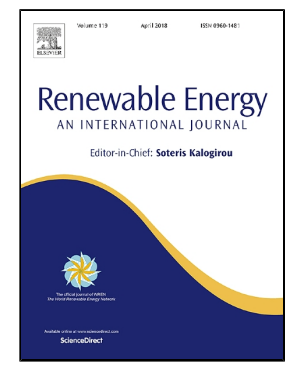

PII: $\quad$ S0960-1481(18)30130-7

DOI: $\quad$ 10.1016/j.renene.2018.01.120

Reference: $\quad$ RENE 9725

To appear in: $\quad$ Renewable Energy

Received Date: $\quad 17$ May 2017

Revised Date: $\quad 28$ December 2017

Accepted Date: $\quad 30$ January 2018

Please cite this article as: Yingying Zheng, Bryan M. Jenkins, Kurt Kornbluth, Chresten Træholt, Optimization under Uncertainty of a Biomass-Integrated Renewable Energy Microgrid with Energy Storage, Renewable Energy (2018), doi: 10.1016/j.renene.2018.01.120

This is a PDF file of an unedited manuscript that has been accepted for publication. As a service to our customers we are providing this early version of the manuscript. The manuscript will undergo copyediting, typesetting, and review of the resulting proof before it is published in its final form. Please note that during the production process errors may be discovered which could affect the content, and all legal disclaimers that apply to the journal pertain. 


\section{Optimization under Uncertainty of a Biomass-Integrated Renewable Energy Microgrid with Energy Storage}

4 a Department of Biological and Agricultural Engineering, University of California, Davis, One Shields Avenue,

5 Davis, Ca 95616, USA

$6 \quad{ }^{b}$ Department of Electrical Engineering, Technical University of Denmark, Elektrovej, 2800 Kgs. Lyngby, Denmark

\section{Nomenclature}
Abbreviations
MG microgrid
CHP combined heat and power
BCHP biomass-based CHP
GS biomass gasifier
ICE internal combustion engine
WT wind turbine
PV photovoltaic
ES energy storage
BT battery
PGS producer gas storage
TES thermal energy storage
HOB heat-only boiler
MCS Monte Carlo simulation
COE cost of energy
PDF probability density function

\section{Symbols}
E electricity demand (kWh)
$\mathrm{H}$ heat demand ( $\mathrm{kWh})$
$\mathrm{Z} \quad$ net acquisition cost (\$)
$\mathrm{P} \quad$ purchase and installation (capital) cost $(\$)$
O\&M operation \& maintenance cost $(\$ / \mathrm{kWh})$
F feedstock or fuel cost $(\$ / \mathrm{kWh})$
C hourly capital cost $(\$ / \mathrm{h})$
$\mathrm{M} \quad$ rated capacity $(\mathrm{kW})$
$\mathrm{N} \quad$ expected life (years)
s economic scaling factor
$\mathrm{T} \quad$ length of planning horizon (h)
V set of all system components that contribute to capital cost
$\mathrm{U} \quad$ set of all system components that contribute to O\&M cost
$\mathrm{x}$ decision variable: hourly energy flow $(\mathrm{kWh} / \mathrm{h})$

\section{Superscripts and subscripts}
t time step (s)
p actual facility 


$\begin{array}{ll}\text { o } & \text { reference facility } \\ \text { i } & \text { index of installed units that contribute to capital cost } \\ \text { j } & \text { index of installed units that contribute to O\&M and fuel } \\ \text { chr } & \text { cost } \\ \text { dis } & \text { discharging } \\ \text { min } & \text { minimum charging and discharging rate }(\mathrm{kWh} / \mathrm{h}) \\ \text { max } & \text { maximum charging and discharging rate }(\mathrm{kWh} / \mathrm{h})\end{array}$

Abstract

Deterministic constrained optimization and stochastic optimization approaches were used to evaluate uncertainties in biomass-integrated microgrids supplying both electricity and heat. An economic linear programming model with a sliding time window was developed to assess design and scheduling of biomass combined heat and power (BCHP) based microgrid systems. Other available technologies considered within the microgrid were small-scale wind turbines, photovoltaic modules (PV), producer gas storage, battery storage, thermal energy storage and heat-only boilers. As an illustrative example, a case study was examined for a conceptual utility grid-connected microgrid application in Davis, California. The results show that for the assumptions used, a BCHP/PV with battery storage combination is the most cost effective design based on the assumed energy load profile, local climate data, utility tariff structure, and technical and financial performance of the various components of the microgrid. Monte Carlo simulation was used to evaluate uncertainties in weather and economic assumptions, generating a probability density function for the cost of energy.

Keywords: microgrids, renewables integration, combined heat and power, biomass, modeling, energy storage, uncertainty, stochastic analysis

\section{Introduction}

Microgrids (MG) are smaller distribution networks usually installed close to the end users, and frequently contain hybrid energy resources, storage devices, and controllable loads. The traditional power grid is generally a large-scale centralized network where power plants generate high voltage electricity that is transferred and distributed to lower voltage end users. A significant fraction of electrical energy is dissipated in delivery due to the long distances between generator and load. Microgrids have been developed around the world as a means to address the high penetration level of renewable generation and reduce greenhouse gas emissions while attempting to address supply-demand balancing at a more local level [1].

The electricity generation of microgrid via solar PV and wind turbines depends, of course, on the total solar radiation and the wind speed in general. Due to the stochastic nature of these renewable energy resources, load behaviors, and market prices, a dispatchable generation unit is frequently included that can be turned on or off or modulated to adjust power output accordingly. The most common dispatchable units are diesel, natural gas, or biomass powered enginegenerators. Moreover, an energy storage system is adopted in most cases to neutralize mismatch between generation and demand and tackle the uncertainty of demand forecasts. Energy storage 
provides the necessary means to shift the microgrid supply to a higher market price period based on the time of use. As an alternative to energy storage, load shifting can be applied to match demand with renewable energy generation. Load shedding may also be feasible, or other types of generation added to ensure demand is satisfied [2]. MG can also be operated with connection to the central power grid, in which case the central grid is used as a backup to reduce or eliminate the need for local storage, or while completely disconnected from the central grid or islanded [3]. When connected, the customer sometimes has the option of selling surplus electricity back to the utility grid operator under a net metering, feed-in, or other power purchase agreement.

In microgrid applications, both manufacturers and customers are interested to know the optimal capacity of the associated components of the system and the dispatch strategy to use in order to minimize cost and environmental impacts. Due to the computational complexity, a number of software packages have been developed to assist in microgrid design and assessment including HOMER [4-8] and DER-CAM [9-11]. Rohit et al. [12] proposed a hybrid off-grid system for a rural application with HOMER. Braslavsky et al. [13] presented an economic model of a shopping center, developed in DER-CAM, using on-site-specific demand, tariffs, and performance data for each technology option available.

Furthermore, substantial studies on microgrid optimal design and operation are typically formulated as minimization or maximization problem constrained by energy demand, capacity limits, ramping rate, and startup or shutdown times [14-21], and most address electricity only although thermal loads may also exist. Both thermal and electrical load profiles can fluctuate hourly and seasonally and utility tariff prices for natural gas and electricity may change dynamically as well. In these cases, electricity-led assumptions cannot guarantee an optimal solution overall. A number of modeling studies incorporating CHP units in the microgrid have considered both electricity and thermal demand [22-29] but few address biomass integration including separation of the fuel production and power generation components.

Variables that are subject to uncertainty in microgrid design and operation include unscheduled maintenance, climatic conditions (e.g. wind and cloudiness), and energy market prices and demands [30-40]. Model prediction control and receding horizon control (RHC) are frequently used to predict and make decisions under uncertainty [41-47]. Jiang and Fei addressed the problem of adopting multiple CHPs for cost reduction in microgrid using hierarchical optimization [48]. Xie et al. [49] developed a look-ahead optimal control algorithm for dispatching the generation units with the objective of minimizing both generation and environmental costs. Silvente et al. [50] used the RHC approach to analyze uncertainty in both energy generation and demand. Monte Carlo simulation (MCS) has been widely used to evaluate the reliability of a microgrid by generating data from fixed probability distributions of stochastic variables, such as wind speed, solar irradiance, customer demands, and others [51-55].

Currently most of the CHP integrated microgrid sizing and scheduling studies have assumed the CHP system as a single unit. However, where a fuel generation unit, such as a biomass gasifier, is deployed, producer gas production and electricity generation can also be treated as two separate and independent processes. The producer gas after biomass gasification can be used directly to fuel an internal combustion engine, microturbine, or another prime mover for power generation, and also used in a furnace or boiler for heat generation to offset utility natural gas demand [56]. Most studies considering energy storage include thermal storage or 84 battery; separate gas storage is typically not considered, instead relying on pipeline supply as the 
storage equivalent and thereby subject to utility pricing. Biomass integrated models using RHC to schedule combined fuel gas generation and storage, engine cogeneration, auxiliary boiler and thermal energy storage operations have not previously been developed.

To address the above-mentioned issues, a model was developed to optimize the design and scheduling of an integrated biomass combined heat and power microgrid (BCHP-MG) system. The model combines a deterministic optimization module with a stochastic module and Monte Carlo simulation. Developing a more general model capable of solving for the optimal configuration and dispatch of a renewable energy microgrid with the flexibility of biomass integration was the primary objective for this work. Specifically, the objectives include: 1) finding the optimal capacity of wind and PV generation in each proposed scenario, 2) developing an optimal dispatch strategy between the various BCHP, wind turbine (WT), PV, battery (BT), producer gas storage (PGS), thermal energy storage (TES), and heat-only boiler (HOB) components of the microgrid and the main utility grid (electricity and natural gas) based on hourly energy demands and tariff rates, 3) estimating the effects of BT capacity on the cost of energy (COE) for different scenarios, 4) evaluating the influence of tariff rates and demand profiles on the $\mathrm{COE}$ and unit dispatch strategies, and 5) investigating the impact of stochastic variables on the final COE probability distribution.

\section{Model development}

\subsection{Microgrid system design}

For quantifying the analysis, microgrid systems with the following components are considered (Fig.1):

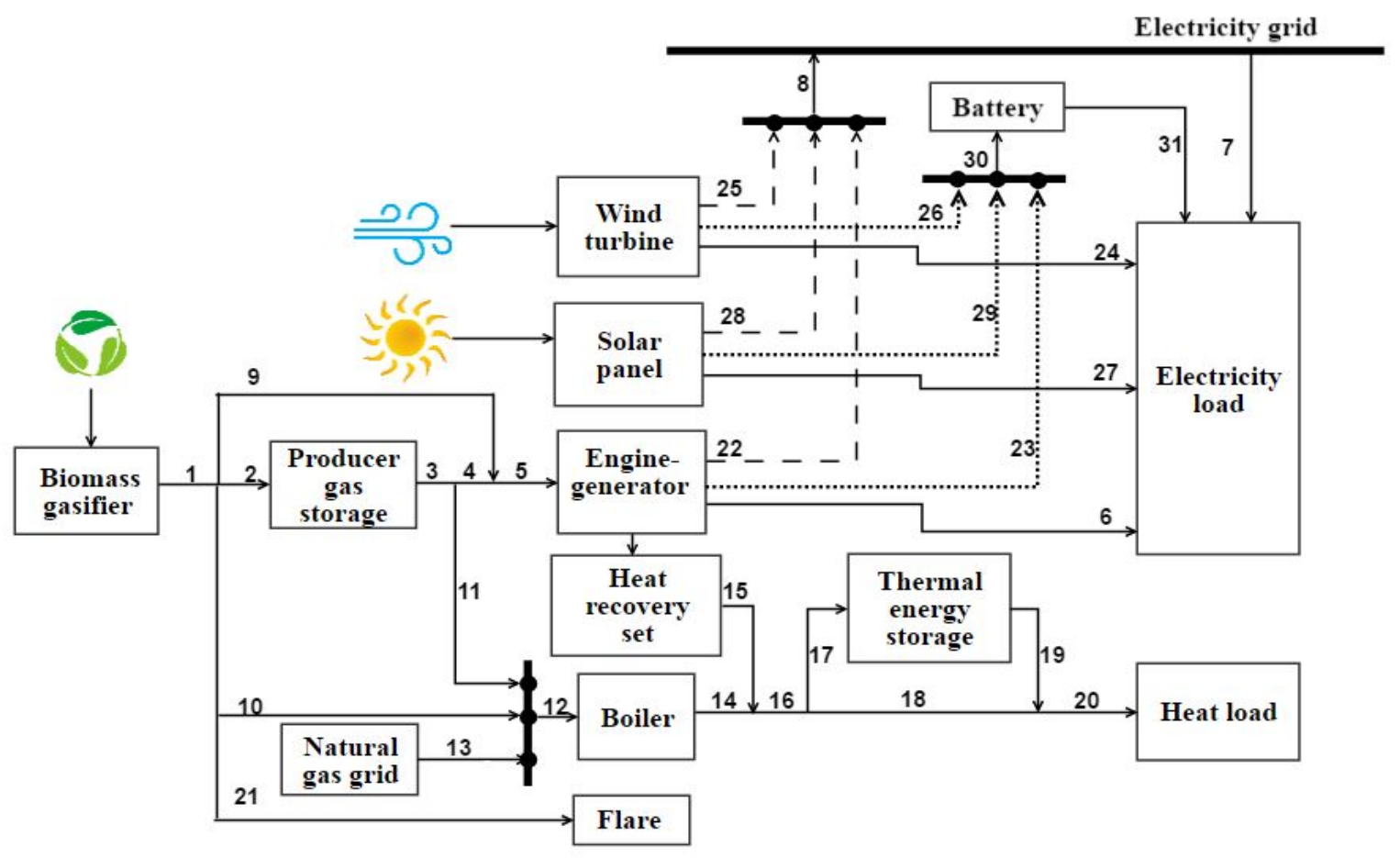


The electricity demand is met by the sum of the BCHP, WT, PV generation and the BT discharge, within their operating limits and constraints. The electricity generated via the PV array and WT depends on the solar radiation and the wind speed in general. The power from the BCHP, WT and PV modules is allowed to charge the BT, depending on the operating strategy selected. Producer gas from the BCHP unit is assumed to be purified and cooled, and can be used directly as fuel for the engine-generator sets and the boiler, stored in the producer gas storage tank, or simply flared for disposal if no economic demand exists and storage is at full capacity [57]. The PGS can be charged when the energy demand is low and discharge during high demand to improve system reliability. It can also be deployed to increase export electricity under a power purchase agreement to raise system revenue when the utility price is high if on a time of use tariff. For internal combustion reciprocating-type engines, heat for other uses can typically be recovered from the engine cooling jacket, exhaust, and potentially the engine surfaces in a combined heat and power mode. The recovered heat can be employed for a number of purposes, including direct heat utilization but also chilling, cooling, and additional electricity generation in a combined cycle mode although the latter is not included here. Similar to PGS, the recovered thermal energy can be used immediately or stored in a thermal energy storage system, in this case a warm water tank is assumed. The auxiliary HOB operates to make up any heat shortage, with heat otherwise supplied from producer gas burned directly from the gasifier, producer gas taken from storage (PGS), or utility natural gas.

For utility grid-connected scenarios, any electricity or heat supply deficits from the microgrid are satisfied by purchasing electricity or natural gas from the utility. In some circumstances surplus electricity from the microgrid is available for delivery to the utility under a net metering, feed-in tariff, or other power purchase arrangement generating revenue for the microgrid operation.

\subsection{Microgrid component modeling}

\subsubsection{BCHP}

$\mathrm{BCHP}$ is assumed to operate as a load following power plant and alter its output to meet varying demands within the capacity limit.

$$
\mathrm{P}_{\mathrm{BCHP}}(\mathrm{t})=f(\text { load })
$$

In the case of BCHP, routine maintenance is required, but there is also the risk of unscheduled outages due to mechanical and other failures. In this study both the gasifier and engine are assumed to have a certain failure risk for unscheduled maintenance and would not be available for generation. The gasifier and engine failures are assumed to be independent, so that the gasifier or the engine may be available when the other fails. Both the gasifier and engine operation are treated as binary being either on (1) or off (0) with variable capacity when the units are on. The probability density function of the Bernoulli distribution is used to represent the stochastic nature of gasifier and engine.

$f(0)= \begin{cases}1 & \text { for } P_{f} \leq x<1 \\ 0 & \text { for } 0 \leq x \leq P_{f}\end{cases}$

Where $f(O)$ is the operating mode of the gasifier or engine (independent); $P_{f}$ is the failure chance of gasifier or engine. 


\subsubsection{Wind turbine}

Wind power generation depends on wind speed and the interference of the turbine with the wind. The output power of the turbine can be one of these three values [44]:

$\mathrm{P}_{w t}(\mathrm{t})=\left\{\begin{array}{l}0 \\ \frac{1}{2} \mathrm{C}_{\mathrm{p}} \rho \mathrm{A}_{\mathrm{wt}} \mathrm{V}(\mathrm{t})^{3} \\ \frac{1}{2} \mathrm{C}_{\mathrm{p}} \rho \mathrm{A}_{\mathrm{wt}} \mathrm{V}_{\text {rated }}^{3}\end{array}\right.$

$$
\begin{aligned}
\text { if } \mathrm{V}(\mathrm{t})< & \mathrm{V}_{\text {cutin }} \text { or } \mathrm{V}(\mathrm{t})>\mathrm{V}_{\text {cutout }} \\
& \text { if } \mathrm{V}_{\text {cutin }}<\mathrm{V}(\mathrm{t})<\mathrm{V}_{\text {rated }} \\
& \text { if } \mathrm{V}_{\text {rated }}<\mathrm{V}(\mathrm{t})<\mathrm{V}_{\text {cutout }}
\end{aligned}
$$

Where $P_{w t}$ is the mechanical output power of the turbine (W), $\rho$ is air density $\left(\mathrm{kg} / \mathrm{m}^{3}\right), A_{w t}$ is the turbine swept area $\left(\mathrm{m}^{2}\right), V$ is the undisturbed wind speed $(\mathrm{m} / \mathrm{s}), \mathrm{C}_{\mathrm{p}}$ is the performance coefficient (or power coefficient) of the turbine, and $\mathrm{V}_{\text {cutin, }} \mathrm{V}_{\text {rated }}$ and $\mathrm{V}_{\text {cutout }}$ are the cut in, rated, and cut out wind speed $(\mathrm{m} / \mathrm{s})$ of the turbine.

Probability density functions (PDF) were used to characterize the stochastic behavior of wind speed. The wind speed over a predefined time period was estimated using a Weibull PDF [55].

$f(V)=\frac{k}{c}\left(\frac{V}{c}\right)^{k-1} \exp \left(-\left(\frac{V}{c}\right)\right)^{k}$

$\mathrm{k}=\left(\frac{\sigma}{\mu}\right)^{-1.086}$

$$
c=\frac{\mu}{\Gamma\left(1+k^{-1}\right)}
$$

Where $f(V)$ is the frequency rate of wind velocity; $c$ is the Weibull scale parameter, a measure of the characteristic wind speed of the distribution; $\mathrm{k}$ is the Weibull shape parameter and specifies the shape of a Weibull distribution, taking on a value of between 1 and 3 ; $\mu$ is the mean wind speed $(\mathrm{m} / \mathrm{s})$ and $\sigma$ is the standard deviation of the wind speed $(\mathrm{m} / \mathrm{s})$. The parameters $\mathrm{k}$ and $\mathrm{c}$ can be computed from $\mu$ and $\sigma$. A small value for $\mathrm{k}$ signifies highly variable winds, while constant winds are characterized by a larger $\mathrm{k}$.

\subsubsection{Photovoltaic module}

The output power of the PV is given by the following equation [58] :

$P_{p v}(t)=\eta_{p v} A_{p v} S$

Where $\mathrm{P}_{\mathrm{pv}}$ is the output power of the PV (W), $\boldsymbol{\eta}_{\mathrm{pv}}$ denotes the conversion efficiency of the PV array $(\%)$ including the intrinsic module efficiency and array shading factor as appropriate, $A_{p v}$ is the array area $\left(\mathrm{m}^{2}\right)$, and $\mathrm{S}$ is the solar radiation, treated as a random variable $\left(\mathrm{W} / \mathrm{m}^{2}\right)$.

Solar irradiation is a stochastic variable that depends on the weather conditions and possible changes in shading throughout the day. Local shading or terrain effects that may also 
177 influence the resource availability are highly site-specific and not part of this analysis. The

178 probabilistic nature of solar irradiance is considered to follow a beta PDF [59].

$f(S)=\frac{\Gamma(\alpha+\beta)}{\Gamma(\alpha)+\Gamma(\beta)} S^{(\alpha-1)}(1-S)^{\beta-1}, \quad \alpha \geq 0, \beta \geq 0$

$180 \quad \beta=(1-\mu)\left(\frac{\mu(1+\mu)}{\sigma^{2}}-1\right)$

$181 \quad \alpha=\frac{\mu \beta}{1-\mu}$

$182(10)$

183 Where $\alpha$ and $\beta$ are the function parameters and $\mathrm{S}$ is the horizontal solar irradiance $\left(\mathrm{kW} / \mathrm{m}^{2}\right) ; \alpha$

184 and $\beta$ are calculated from the mean and standard deviation of solar irradiance $\mu$ and $\sigma$. Similar to

185 the wind speed, an hourly average solar irradiance is used.

186 2.2.4. Energy storage

187 As an energy storage device, the battery storage injects power to the microgrid when the 188 local generation is insufficient and absorbs power from the microgrid when the local generation 189 is abundant or a model decision criterion indicates that saving the electrical energy for the future 190 hours would increase net economic benefit. Producer gas storage can be charged when the 191 producer gas production is abundant or a model decision criterion decides that storing the 192 producer gas for future generation either as electricity or heat would improve the value of the 193 objective function. Thermal energy storage was modeled as sensible heat storage, using water as 194 the storage medium, and considering only energy flows through the warm water storage tank.

\subsection{Mathematical formulation}

\subsubsection{Decision variables}

Decision variables express the microgrid operating modes and the energy flows $(\mathrm{kWh} / \mathrm{h})$

198 between system components. The $x$ variables define the energy flows throughout the microgrid 199 system, each labeled with a subscript denoting the specific energy transfer (Fig. 1). The variables 200 mentioned, along with other energy transfers, are now defined according to this notation. Each

Table 1 Decision variables.

\begin{tabular}{llll}
\hline $\begin{array}{c}\text { Decision } \\
\text { variables }\end{array}$ & & Energy Flow from & Energy Flow in to \\
\hline & x1 & gasifier & \\
& x2 & gasifier & gas storage \\
x3 & gas storage & \\
x4 & gas storage & engine \\
BCHP & x5 & & engine \\
& x6 & engine & electricity demand \\
& x7 & electricity grid & electricity demand \\
& x8 & & electricity demand \\
x9 & gasifier & engine \\
\hline
\end{tabular}




\begin{tabular}{|c|c|c|c|}
\hline & $\mathrm{x} 10$ & gasifier & boiler \\
\hline & $\mathrm{x} 11$ & storage & boiler \\
\hline & $\mathrm{x} 12$ & & boiler \\
\hline & $\mathrm{x} 13$ & natural gas grid & boiler \\
\hline & x14 & boiler & \\
\hline & $\mathrm{x} 15$ & engine heat recovery & thermal demand \\
\hline & $\mathrm{x} 16$ & thermal production & \\
\hline & $\mathrm{x} 17$ & thermal production & thermal storage \\
\hline & $\mathrm{x} 18$ & thermal production & heating demand \\
\hline & $\mathrm{x} 19$ & thermal storage & heating demand \\
\hline & $\mathrm{x} 20$ & & heating demand \\
\hline & $\mathrm{x} 21$ & gasifier & flare \\
\hline & $\mathrm{x} 22$ & engine & electricity grid \\
\hline & $\mathrm{x} 23$ & engine & battery \\
\hline & $\mathrm{x} 24$ & wind turbine & electricity demand \\
\hline WT & $\mathrm{x} 25$ & wind turbine & electricity grid \\
\hline & $\mathrm{x} 26$ & wind turbine & battery \\
\hline & $\mathrm{x} 27$ & solar panel & electricity demand \\
\hline PV & $\mathrm{x} 28$ & solar panel & electricity grid \\
\hline & $\mathrm{x} 29$ & solar panel & battery \\
\hline BT & $\mathrm{x} 30$ & & battery \\
\hline & x31 & battery & electricity demand \\
\hline
\end{tabular}

\subsubsection{Objective function}

The optimization in this case is developed from the objective to minimize the cost of energy of over a particular time horizon (T) using an hourly time base. The objective function is

207 formulated as:

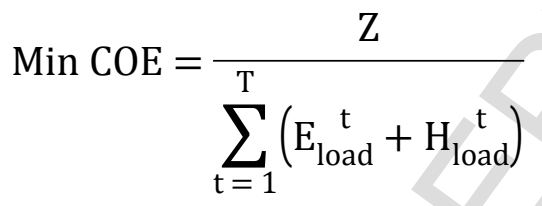

210 Where $\mathrm{Z}$ is the net energy supply cost $(\$) ; \mathrm{E}_{\text {load }}$ and $\mathrm{H}_{\text {load }}$ are the electricity and heating demand 211 ( $\mathrm{kWh}) ; \mathrm{T}$ is the length of the planning horizon (h) and $\mathrm{t}$ is the time step.

212 The net energy supply cost consists of the levelized fixed or capital costs of the system, 213 the feedstock and fuel supply costs, and all operating and maintenance (O\&M) costs, all resolved

214 to a uniform cost of energy considering the time value of money. Capital and O\&M costs in 215 general are subject to economies of scale and hence influenced by the size of the units included 216 in the system [60]. Feedstock and O\&M costs assumed not to be subject to economies of scale 217 although in practice pricing may depend on supply quantities. 
$C_{i}=\frac{P_{i} \quad \operatorname{ir}(1+i r)^{N}}{8760(1+i r)^{N}-1}$

$220 \quad$ (13)

$\frac{\mathrm{P}_{\mathrm{p}}}{\mathrm{P}_{\mathrm{o}}}=\left(\frac{\mathrm{M}_{\mathrm{p}}}{\mathrm{M}_{\mathrm{o}}}\right)^{\mathrm{s}}$

222

223

224

225

226

227

228

229

230

231

232

Where $\mathrm{V}$ is the set of all installed system components that contribute to capital cost; $\mathrm{i}$ is the index for all the installed units that contribute to capital cost; $\mathrm{U}$ is the set of all energy flows that create O\&M and fuel cost; $\mathrm{j}$ is the index for the energy flows that create O\&M and fuel cost; $\mathrm{C}$ is the hourly levelized capital cost (\$); O\&M and $\mathrm{F}$ are the hourly O\&M and fuel cost of energy flow $\mathrm{j}$ at time $\mathrm{t}(\$ / \mathrm{kWh}) ; \mathrm{x}$ is the energy flow $(\mathrm{kWh}) ; \mathrm{P}$ is the overnight purchase and installation cost that is influenced by an economy of scale defined by the value of $\mathrm{s}(0 \leq \mathrm{s} \leq 1)$ [61]; ir is the interest rate, and $\mathrm{N}$ is expected life time (y). The constant 8760 is the conversion for the number of hours per year and is uncorrected for leap years. For the equation defining the economy of scale, $P_{p}$ is the capital cost of facility or unit under consideration within the microgrid; $P_{o}$ is the known capital cost of a reference facility or unit of the same type, $M_{p}$ is the rated capacity of the unit under consideration; $\mathrm{M}_{0}$ is the rated capacity of the reference unit.

\subsubsection{Constraints}

All energy flows $\left(\mathrm{x}_{1-31}\right)$ are signed with lower (zero) and upper bounds with the latter being the maximum acceptable capacities. The electricity balance constraints the electrical demand to be satisfied by BCHP, WT, PV, BT or the grid power. The heat balance constraints the heating demand to be satisfied by the producer gas powered boiler, the natural gas powered boiler, the heat recovered from engine generator set, or some combination of these sources. Therefore, the energy balances at time $t$ for the microgrid can be written as follows:

$\mathrm{x}_{6}^{\mathrm{t}}+\mathrm{x}_{7}^{\mathrm{t}}+\mathrm{x}_{24}^{\mathrm{t}}+\mathrm{x}_{27}^{\mathrm{t}}+\mathrm{x}_{31}^{\mathrm{t}}=\mathrm{E}_{\text {load }}^{\mathrm{t}}$

$\mathrm{x}_{20}^{\mathrm{t}}=\mathrm{H}_{\text {load }}^{\mathrm{t}}$

The BT and PGS storage levels at the current time step $t$ depend on the storage level at previous time step (t-1) and the current charging or discharging rate. The BT and PGS energy balances are:

$\mathrm{BT}^{\mathrm{t}}=\mathrm{BT}^{\mathrm{t}-1}+\mathrm{x}_{30}^{\mathrm{t}}-\mathrm{x}_{31}^{\mathrm{t}}$

$$
\mathrm{PGS}^{\mathrm{t}}=\mathrm{PGS}^{\mathrm{t}-1}+\mathrm{x}_{2}^{\mathrm{t}}-\mathrm{x}_{3}^{\mathrm{t}}
$$

Where $\mathrm{BT}^{\mathrm{t}}$ and PGS ${ }^{\mathrm{t}}$ are the energy storage level at current time step $\mathrm{t}, \mathrm{BT}^{\mathrm{t}-1}$ and $\mathrm{PGS}^{\mathrm{t}-1}$ the amounts of energy stored in BT and PGS at previous time step t-1.

Storage level constraints require that storage levels should be in the range between the minimum and maximum determined safety and economy. The constraints of charging and 
discharging indicate the changing rate for BT and PGS should be within the upper and lower limits. The maximum charge and discharge rate is for the model developed here assumed to be half of the rated capacity. The charging and discharging efficiencies of BT and PGS are assumed small although this is not a general constraint of the model. The constraints for TES are as same as BT and PGS.

$$
\mathrm{BT}_{\text {min }} \leq \mathrm{BT}^{\mathrm{t}} \leq \mathrm{BT}_{\text {max }}
$$

$\mathrm{BT}_{-} \mathrm{chr}_{\min } \leq \mathrm{x}_{30}^{\mathrm{t}} \leq \mathrm{BT}_{-} \mathrm{chr}{ }_{\max }$

$$
\text { BT_dis }_{\text {min }} \leq \mathrm{x}_{31}^{\mathrm{t}} \leq \mathrm{BT}_{-} \text {dis }{ }_{\max }
$$

PGS_dis $_{\text {min }} \leq \mathrm{x}_{3}^{\mathrm{t}} \leq$ PGS_dis $_{\text {max }}$

$\left|\mathrm{x}_{6}^{\mathrm{t}}-\mathrm{x}_{6}^{\mathrm{t}-1}\right| \leq \mathrm{E}_{-}$ramp rate

Where $\mathrm{x}_{1}$ is the biomass gasifier production at time $t ; \mathrm{x}_{6}$ is the ICE production at time $t ; \mathrm{G}_{-}$ ramp $_{\text {rate }}$ and $\mathrm{E}_{-}$ramp $p_{\text {rate }}$ are the ramping rates of the gasifier and the engine-generator, which is related to the capacity and type.

Some decision variables are coupling with each other and constrained by energy balance, for example:

$\mathrm{x}_{1}^{\mathrm{t}}=\mathrm{x}_{2}^{\mathrm{t}}+\mathrm{x}_{9}^{\mathrm{t}}+\mathrm{x}_{10}^{\mathrm{t}}+\mathrm{x}_{21}^{\mathrm{t}}$

\section{(27)}

Where $\mathrm{x}_{2}, \mathrm{x}_{9}, \mathrm{x}_{10}$, and $\mathrm{x}_{21}$ represents the energy flow out of biomass gasifier to either gas storage, engine, boiler, or flare, respectively (Table 5). Similar energy balance constraints are shown in Fig. 1.

This mathematical formulation of the system design and unit commitment problem is a linear convex optimization problem. The model implementation was here solved using MATLAB with its optimization toolbox (MATLAB 2016a, Mathworks, Natick, Massachusetts). ${ }^{1}$

\footnotetext{
${ }^{1}$ mention of a specific tradename does not constitute an endorsement by the University of California.
} 


\subsection{Solution method}

The model discussed here chains a deterministic planning optimization module with a stochastic module (Fig. 2).

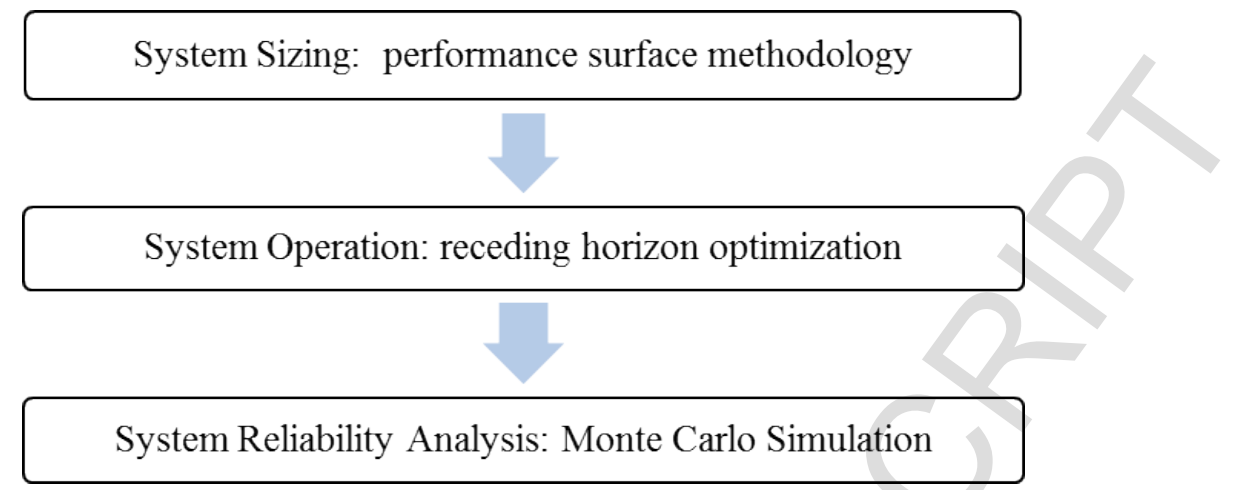

Fig. 2. Microgrid optimization modules.

\subsubsection{Performance surface method}

The model is first solved deterministically to derive the optimal wind and solar capacities for each proposed microgrid scenario. The capacity of WT and PV units is gradually increased from none to $250 \mathrm{~kW}$ (with $10 \mathrm{~kW}$ of increment) in a search for the optimal capacity yielding minimum cost with the rest of units fixed. The criterion of selecting the best hybrid energy system combination for a proposed site is based on minimizing the cost for different renewable combinations, the output of the optimal sizing and operation being the preferred set of WT and PV modules. The entire procedure is repeated for all the possible combinations. The combination with the lowest cost overall is selected as optimal design for each scenario.

\subsubsection{Sliding time window}

Once all the unit capacity has been fixed, the dispatch of the available units to meet demand at the lowest cost is required. The hourly operation strategy of the different hybrid configurations is determined by using linear constrained optimization. The sizing and operating strategies are interdependent so a different set of component configurations is analyzed in each hybrid combination to find the optimal hybrid system.

A sliding time window method is used to first determine the optimal operation of all microgrid components $[43,50]$. For the examples included here, a 4-hour time window is used with known electrical and heat demand. Each hour has a total of 31 solution variables (Fig. 1), which for a 4-hour horizon requires solving for 124 variables. Within each time window, linear optimization is applied to obtain the gasifier, gas storage, engine, boiler, thermal storage, WT, $\mathrm{PV}$ and BT operation giving the minimum operating cost. Only the solution for the first hour is retained to compute the actual generation and cost. At the same time, the new initial conditions of all the energy storage devices including the BT, PGS, TES units are updated. The time window is then incremented by one hour, and the process repeated for the entire time horizon (27 hours for a 24 hour period). The sliding time window approach is summarized in the following steps (Fig. 3). 


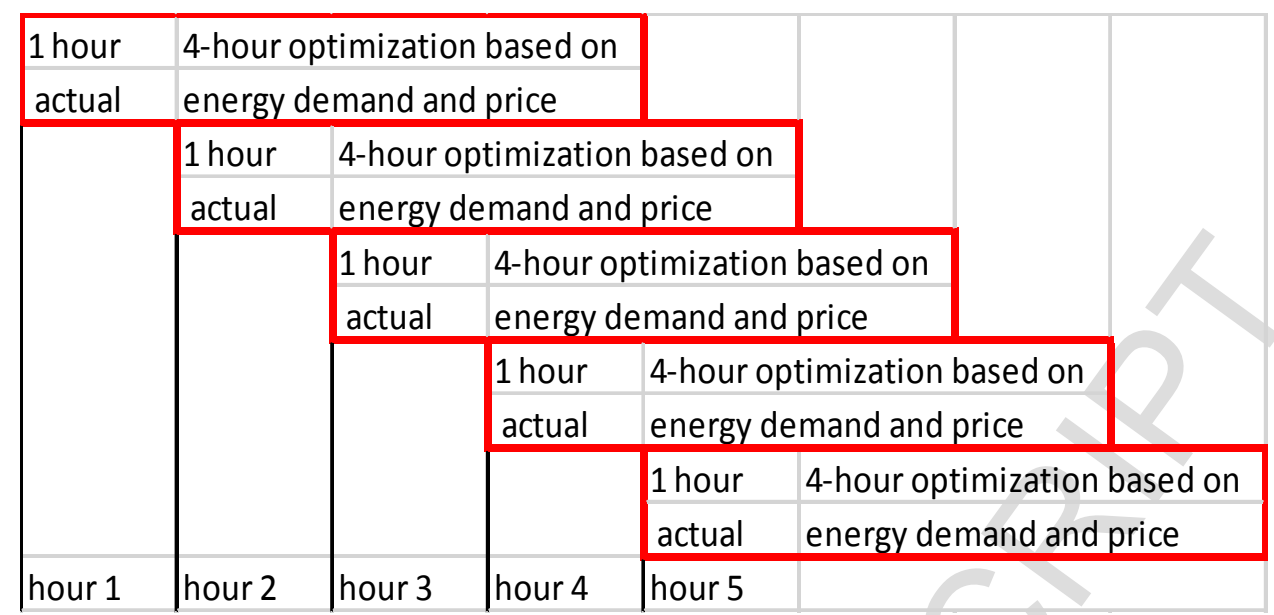

Fig. 3. Sliding window method (4-hour window illustrated over a period of 5 hours).

1. Specify initial conditions of energy storages.

2. Optimize the system operation as outlined above for the period from $t$ initial to $t$ initial+ $\mathrm{T}$ (T: sliding time window width).

3. Obtain the optimal operating points of all units.

4. Set the operating conditions of the first hour of the window to the optimal conditions.

5. Update energy storage conditions.

6. Slide the window 1 hour forward in time.

7. Repeat from step 2 .

\subsubsection{Monte Carlo simulation}

Monte Carlo simulation was conducted to generate a finite number of possible outcomes based on the probability distributions of assumed stochastic parameters. A total of 1000 Monte Carol simulations were used to generate the cost of energy distributions for each scenario. The distribution of simulated outcomes for the 1000 realizations of the COE provided the risk profile.

\section{Model application}

\subsection{Case study definition}

The input data for the model were divided into the following categories: 1) customer information (load profile and weather data), 2) technical information (physical characteristics and specifications of all units, efficiency, heat to power ratio, power generation PDF, etc.), 3) financial information (capital cost, O\&M cost, fuel costs, tariff rate). In the deterministic model, the output of the model is the optimal microgrid design and dispatch (based on the COE values). In the stochastic model, the output of the model is the probability distribution of COE.

For the case study located in Davis, California, a typical winter daily residential electricity load profile from the local utility was scaled up and used for analysis. A winter daily thermal demand profile from the UC Davis campus was scaled down to represent thermal energy usage (Fig. 4). The studied microgrid scale is around $100 \mathrm{~kW}$. Therefore, the input load profiles are scaled up or down to the desired range. For the scenario analyses, the peak and base load demand for electricity and heating were in the range of $72-200 \mathrm{~kW}$ and $50-172 \mathrm{~kW}$, respectively. Davis hourly solar and wind data in February were obtained from the California Irrigation Management Information System (CIMIS). 


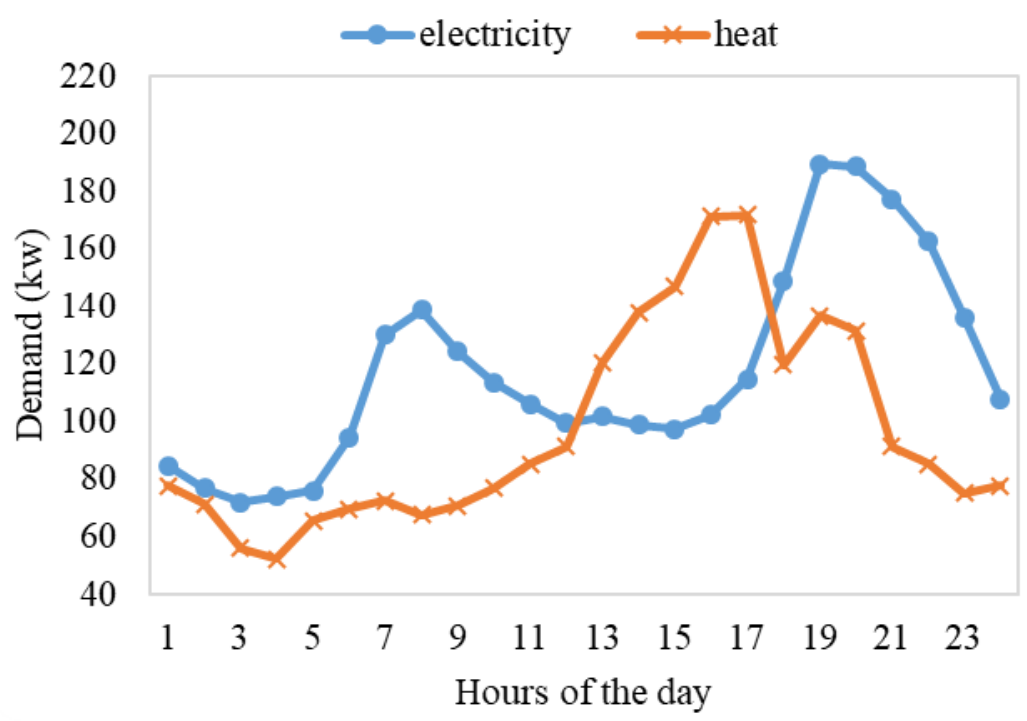

Fig. 4. Model hourly electricity and heat demand for February in Davis, California.

Technical and economic parameters for the wind turbines and PV assumed here are based on a $10 \mathrm{~kW}$ unit capacity. The efficiency and cost of the power converters have been included in the overall PV and wind turbines' efficiencies and costs. All parameters assumed for BCHP is based on a $100 \mathrm{~kW}$ unit capacity. All units are assumed to subject to 20 years life time and $6 \%$ of interest rate (Table 2).

Table 2 Technical parameters and cost assumptions for components of the microgrid [62-65].

\begin{tabular}{llll}
\hline & Parameters & Unit & Value \\
\hline All & Discount/interest rate & $\%$ & 6 \\
& Economic life & years & 20 \\
& Economic scale factor & - & 0.9 \\
\hline BCHP & Rated power & $\mathrm{kW}$ & 100 \\
& Capital cost & $\$ / \mathrm{kW}$ & 4500 \\
& O \& M cost & $\$ / \mathrm{kWh}$ & 0.03 \\
& Feedstock cost & $\$ / \mathrm{kWh}$ & 0.02 \\
& Electricity efficiency & - & 0.3 \\
& Heat recovery factor & - & 0.6 \\
\hline WT & Reference module rated power & $\mathrm{kW}$ & 10 \\
& Reference module rotor diameter & $\mathrm{m}$ & 7 \\
& Capital cost & $\$ / \mathrm{kW}$ & 2154 \\
& O \& M cost & $\$ / \mathrm{kWh}$ & 0.005 \\
& Fuel cost & $\$ / \mathrm{kWh}$ & 0 \\
& Cut-in wind speed & $\mathrm{m} / \mathrm{s}$ & 2.5 \\
Cut-off wind speed & $\mathrm{m} / \mathrm{s}$ & 50
\end{tabular}




\begin{tabular}{llll} 
& Rated wind speed & $\mathrm{m} / \mathrm{s}$ & 11 \\
& Air density & $\mathrm{kg} / \mathrm{m}^{\wedge} 3$ & 1.23 \\
& Betz Coefficient & - & 0.593 \\
\hline PV & Reference module rated power & $\mathrm{kW}$ & 10 \\
& Reference module surface area & $\mathrm{m}^{\wedge} 2$ & 64 \\
& Capital cost & $\$ / \mathrm{kW}$ & 3463 \\
& O \& M cost & $\$ / \mathrm{kWh}$ & 0.005 \\
& Fuel cost & $\$ / \mathrm{kWh}$ & 0 \\
& Electricity efficiency & - & 0.2 \\
\hline BT & Rated capacity & $\mathrm{kWh}$ & 200 \\
& Capital cost & $\$ / \mathrm{kWh}$ & 255 \\
& O \& M cost & $\$ / \mathrm{kWh}$ & 0 \\
& Round trip efficiency & - & 0.9 \\
\hline PGS & Rated capacity & $\mathrm{kWh}$ & 200 \\
& Capital cost & $\$ / \mathrm{kWh}$ & 80 \\
& O \& M cost & $\$ / \mathrm{kWh}$ & 0.005 \\
& Round trip efficiency & - & 1 \\
\hline HOB & Rated power & $\mathrm{kW}$ & 150 \\
& Capital cost & $\$ / \mathrm{kW}$ & 120 \\
& O \& M cost (\$/kWh) & $\$ / \mathrm{kWh}$ & 0.005 \\
& Efficiency & - & 0.85 \\
\hline
\end{tabular}

Both capital and operating costs are also subject to uncertainty. An assumption was made 354 here that all the capital and O\&M costs are uniformly distributed over the range from zero to 355 twice the reference cost, the lower bound representing an extreme incentive case with a high 356 subsidy. The gasifier and engine are both assumed to have $5 \%$ of failure risk for unscheduled 357 maintenance and would not be available for generation. The shape and scale factors for Weibull 358 and Beta distribution are estimated by the curve fitting function in Matlab based on historical 359 wind speed and solar irradiance data. Table 3 lists the 13 uncertainty parameters and their 360 associated PDFs.

Table 3 Stochastic parameters and assumed PDF.

\begin{tabular}{lll}
\hline Stochastic parameter & PDF & PDF specifications \\
\hline BCHP Capital cost $(\$ / \mathrm{kW})$ & Uniform & {$[0,9000]$} \\
WT Capital cost $(\$ / \mathrm{kW})$ & Uniform & {$[0,4308]$} \\
PV Capital cost $(\$ / \mathrm{kW})$ & Uniform & {$[0,6926]$} \\
BT Capital cost $(\$ / \mathrm{kW})$ & Uniform & {$[0,510]$} \\
GS O\&M cost $(\$ / \mathrm{kWh})$ & Uniform & {$[0,0.04]$} \\
ICE O\&M cost $(\$ / \mathrm{kWh})$ & Uniform & {$[0,0.02]$} \\
WT O\&M cost $(\$ / \mathrm{kWh})$ & Uniform & {$[0,0.01]$}
\end{tabular}


362

363

364

365

366

$\begin{array}{lll}\text { PV O\&M cost }(\$ / \mathrm{kWh}) & \text { Uniform } & {[0,0.01]} \\ \text { BT O\&M cost }(\$ / \mathrm{kWh}) & \text { Uniform } & {[0,0.002]} \\ \text { Wind speed }(\mathrm{m} / \mathrm{s}) & \text { Weibull } & \text { Shape factor } \mathrm{k}=1.6337 \text {; scale factor } \mathrm{c}=2.7813 \\ \text { Solar irradiance }\left(\mathrm{w} / \mathrm{m}^{\wedge} 2\right) & \text { Beta } & \text { Shape factor } \mathrm{a}=0.0058 \text {; scale factor } \mathrm{b}=0.070 \\ \text { GS availability } & \text { Bernoulli } & \mathrm{P}_{\mathrm{f}}=0.05 \\ \text { ICE availability } & \text { Bernoulli } & \mathrm{P}_{\mathrm{f}}=0.05\end{array}$

For TOU rates, the price of electricity changes by time of day (Table 4). For natural gas, the price is assumed to be constant throughout the day. The electricity buyback price is assumed to be $\$ 0.04 / \mathrm{kWh}$ based on the net surplus compensation rate approved by the California Public Utilities Commission (CPUC) [66].

Table 4 Electricity tariff rate

\begin{tabular}{llll}
\hline Energy Source & Category & Tariff rate $(\$ / \mathrm{kWh})$ & Time \\
\hline Electricity Buy & off-peak & 0.22 & $00: 00-09: 59 \mathrm{am} ; 09: 00-11: 59 \mathrm{pm}$ \\
& partial-peak & 0.30 & $10: 00-11: 59 \mathrm{am} ; 07: 00-08: 59 \mathrm{pm}$ \\
& peak & 0.40 & $12: 00-06: 59 \mathrm{pm}$ \\
Electricity Sell & all day & 0.04 & N/A \\
Natural gas Buy & all day & 0.08 & N/A \\
\hline
\end{tabular}

Five design configuration scenarios were selected to investigate various aspects of the biomass integrated microgrid optimization (Table 5). All are utility grid interconnected, installed with a $200 \mathrm{~kW} \mathrm{HOB}$ and a $200 \mathrm{kWh}$ TES. A net energy metering agreement is included with compensation for surplus electricity delivered from the microgrid to the utility. BCHP, PV and WT are allowed for connection to a utility meter. Scenario 1 includes only wind and PV generation with battery storage. This option is a good alternative for locations with very limited heat demand but abundant wind and solar resources, or areas without abundant biomass resources. Scenario 2 includes all the all three renewable sources but without producers gas storage. Scenario 3 also includes all three renewable sources with a full complement of producer gas, thermal, and battery storage but the biomass component is insufficient to meet peak load by itself. Scenario 4 is the same as Scenario 3 but with added BCHP capacity, in this case a duplicate unit for a total biomass generation of $200 \mathrm{~kW}$, slightly higher than peak load. Scenario 5 is the presumed conventional system and supplies energy demands entirely from the utility electricity and natural gas grids.

Table 5 System components of the 5 proposed scenarios $(\bullet=$ unit included, $x=$ unit excluded).

\begin{tabular}{lllllll}
\hline Scenario & BCHP_1 & BCHP_2 & WT & PV & PGS & BT \\
\hline 1 & $\mathrm{x}$ & $\mathrm{x}$ & $\bullet$ & $\bullet$ & $\mathrm{x}$ & $\bullet$ \\
2 & $\bullet$ & $\mathrm{x}$ & $\bullet$ & $\bullet$ & $\mathrm{x}$ & $\bullet$ \\
3 & $\bullet$ & $\mathrm{x}$ & $\bullet$ & $\bullet$ & $\bullet$ & $\bullet$ \\
4 & $\bullet$ & $\bullet$ & $\bullet$ & $\bullet$ & $\bullet$ & $\bullet$ \\
5 & $\mathrm{x}$ & $\mathrm{x}$ & $\mathrm{x}$ & $\mathrm{x}$ & $\mathrm{x}$ & $\mathrm{x}$ \\
\hline
\end{tabular}


The lowest COE was found among all the possible combinations of WT and PV modules (WT: 0-250 kW; PV: 0-250 kW) (Table 6).

Table 6 Optimal system combinations.

\begin{tabular}{clll}
\hline Scenarios & System Configuration & $\begin{array}{l}\text { Optimal WT Installed } \\
\text { units }\end{array}$ & $\begin{array}{l}\text { Optimal PV Installed } \\
\text { units }\end{array}$ \\
\hline 1 & BCHP (0), PGS (0), BT (200) & 180 & 170 \\
2 & BCHP (100), PGS (0), BT (200) & 0 & 160 \\
3 & BCHP (100), PGS(200), BT(200) & 0 & 160 \\
4 & BCHP (200), PGS(200), BT(200) & 0 & 130 \\
5 & BCHP (0), PGS(0), BT(0) & N/A & N/A \\
\hline
\end{tabular}

Figs.5-8 illustrate the 3D surface of cost response as a function of the capacities of WT and PV for scenarios 1 to 4 . The optimum WT and PV capacity can be found around the minimum points in the figures. For scenario 1, when no BCHP is considered, the model yields the lowest cost with $180 \mathrm{~kW}$ of wind capacity and $170 \mathrm{~kW}$ of PV capacity. For scenarios 2, 3 and 4 , when BCHP is included, no wind capacity is adopted for the cost structure assumed. The reference installed capital cost for PV was assumed to be $\$ 3165 / \mathrm{kW}$ with $\$ 0.005 / \mathrm{kWh}$ for O\&M; for wind, the reference capital cost was $\$ 2175 / \mathrm{kW}$ with $\$ 0.005 / \mathrm{kWh}$ for O\&M. Although the wind is assumed to have a lower capital cost, the wind speed profile for the site selected (Davis, California) has only 9 hours of the day with speeds above $2.5 \mathrm{~m} / \mathrm{s}$, the cut-in wind speed. Hence, generation is low and generation cost exceeds that of PV. From an economic viewpoint, PV and BCHP are the most attractive technology for this site under these cost assumptions. The optimal outcomes will in general differ depending on location. Comparing scenarios 2 and 3, no change in installed PV capacity is associated with the addition of producer gas storage. For scenario 4,

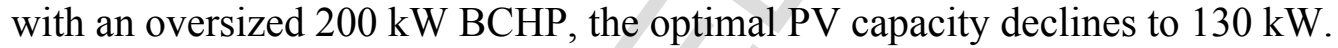

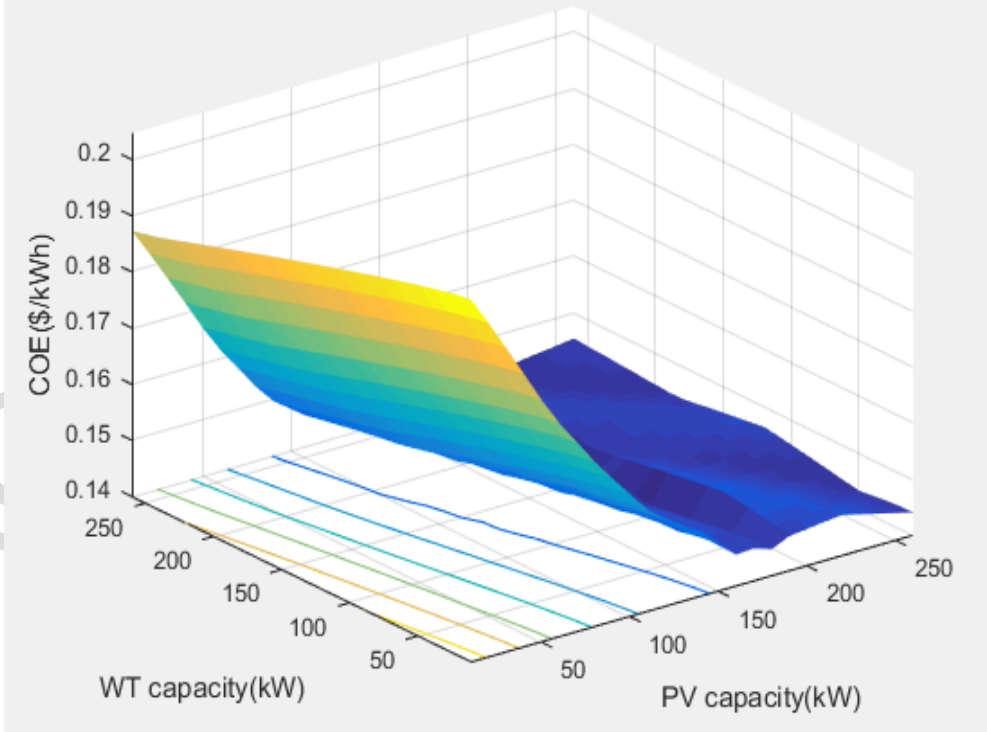

Fig. 5. COE surface of scenario 1 as a function of WT and PV capacities. 


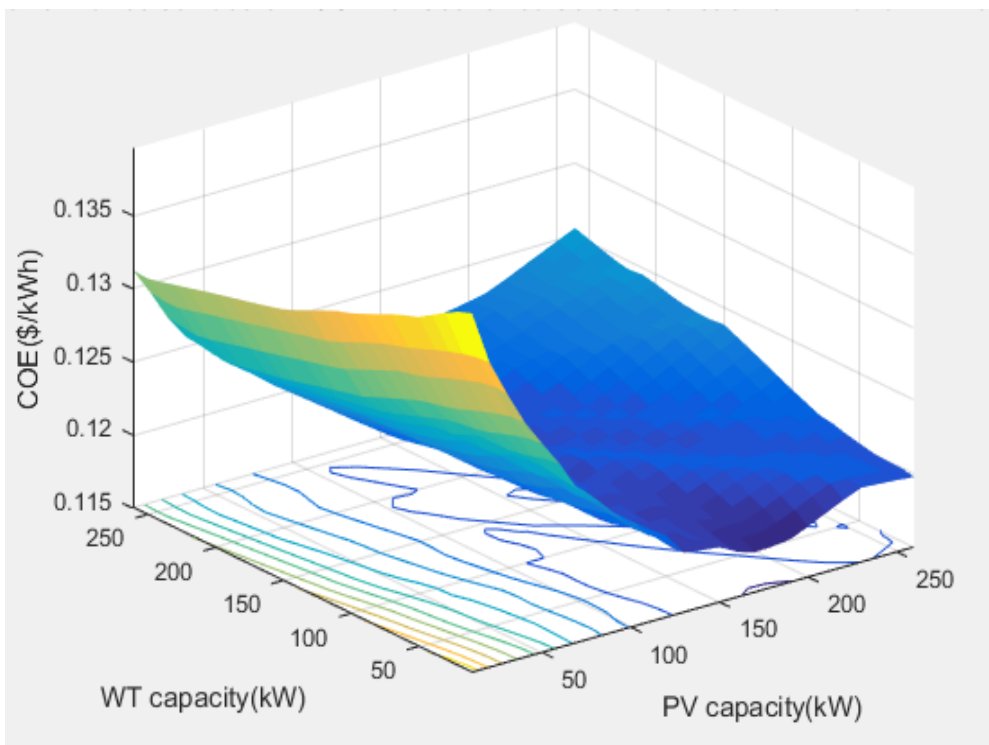

406

Fig. 6. COE surface of scenario 2 as a function of WT and PV capacities.

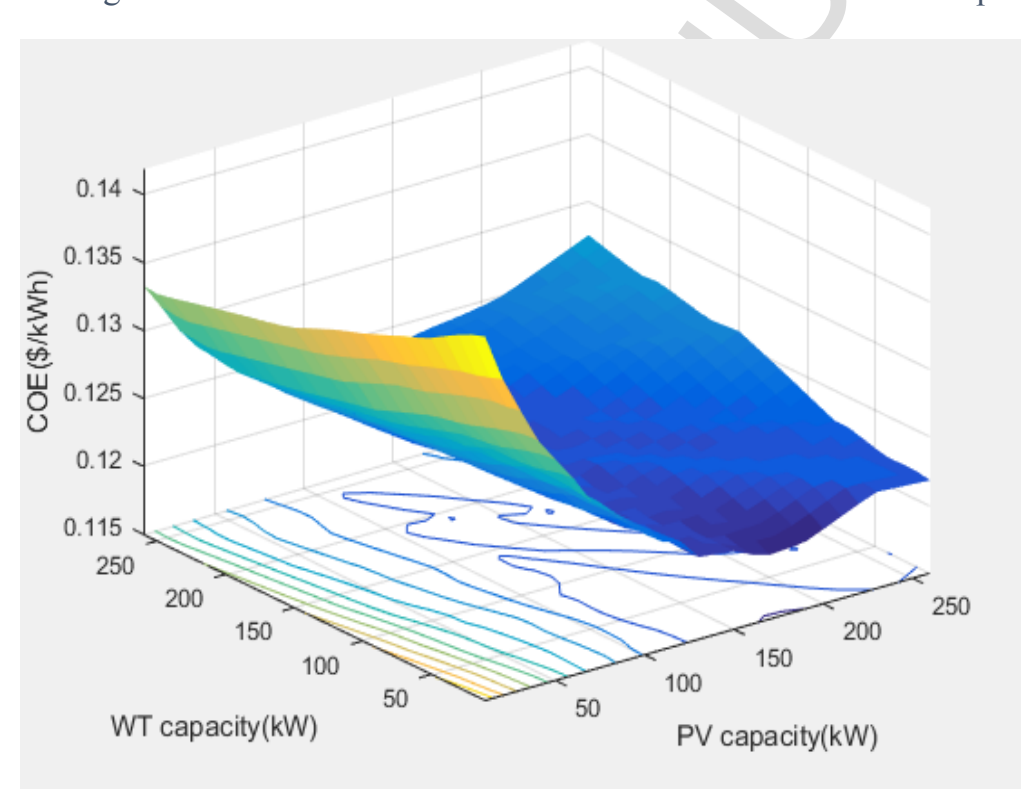

Fig. 7. COE surface of scenario 3 as a function of WT and PV capacities. 


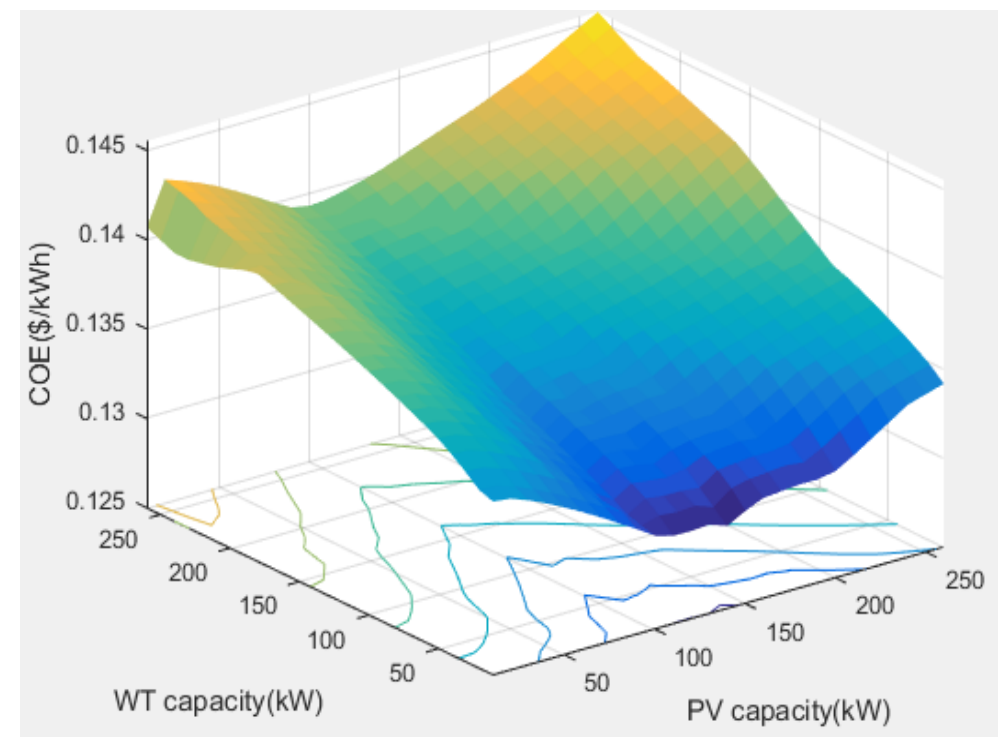

Fig. 8. COE surface of scenario 4 as a function of WT and PV capacities.

For the assumptions used in these examples, the total cost of the optimal system configuration varies from a low of $\$ 0.1182 / \mathrm{kWh}$ for Scenario 2, the $100 \mathrm{~kW}$ BCHP with 200 $\mathrm{kWh}$ battery storage scenario, to a high of $\$ 0.2029 / \mathrm{kWh}$ for Scenario 5, the utility only supply scenario. Scenario 4, with a $200 \mathrm{~kW}$ BCHP capacity and $130 \mathrm{~kW}$ of PV achieves $100 \%$ renewable supply through the microgrid with no utility purchase, but is higher in generation cost than the hybrid microgrids of Scenarios 2 and 3 relying on both microgrid and utility generation. Because of the boiler's installation, there is also installation cost in scenario 5 (Table 7).

Table 7 Optimal COE values and cost composition for 5 scenarios.

\begin{tabular}{llllll}
\hline Composition of total cost (\$) & scenario 1 & scenario 2 & scenario 3 & scenario 4 & scenario 5 \\
\hline Installation & 239.75 & 259.91 & 263.37 & 334.94 & 7.70 \\
O\&M+Fuel & 19.44 & 276.51 & 281.33 & 342.99 & 11.60 \\
Electricity purchase & 290.26 & 55.18 & 55.18 & 0.00 & 804.42 \\
Natural gas purchase & 218.44 & 28.44 & 28.45 & 0.00 & 218.44 \\
Net metering credit & -16.48 & -12.77 & -10.95 & -5.01 & 0.00 \\
Daily total cost & 751.40 & 607.27 & 617.37 & 672.91 & 1042.16 \\
\hline COE $\mathbf{( \$ / k W h )}$ & $\mathbf{0 . 1 4 6 2}$ & $\mathbf{0 . 1 1 8 2}$ & $\mathbf{0 . 1 2 0 2}$ & $\mathbf{0 . 1 3 1 0}$ & $\mathbf{0 . 2 0 2 9}$ \\
\hline
\end{tabular}

Fig. 9 illustrates the economic results for the proposed 5 scenarios. Even with additional capital and installation costs, the introduction of BCHP reduces the need for electricity and natural gas purchases, and the overall total cost and COE are decreased through this on-site generation. In addition, the producer gas storage does not lead to obvious economic gains, due to the low cost assumed for purchased natural gas. 


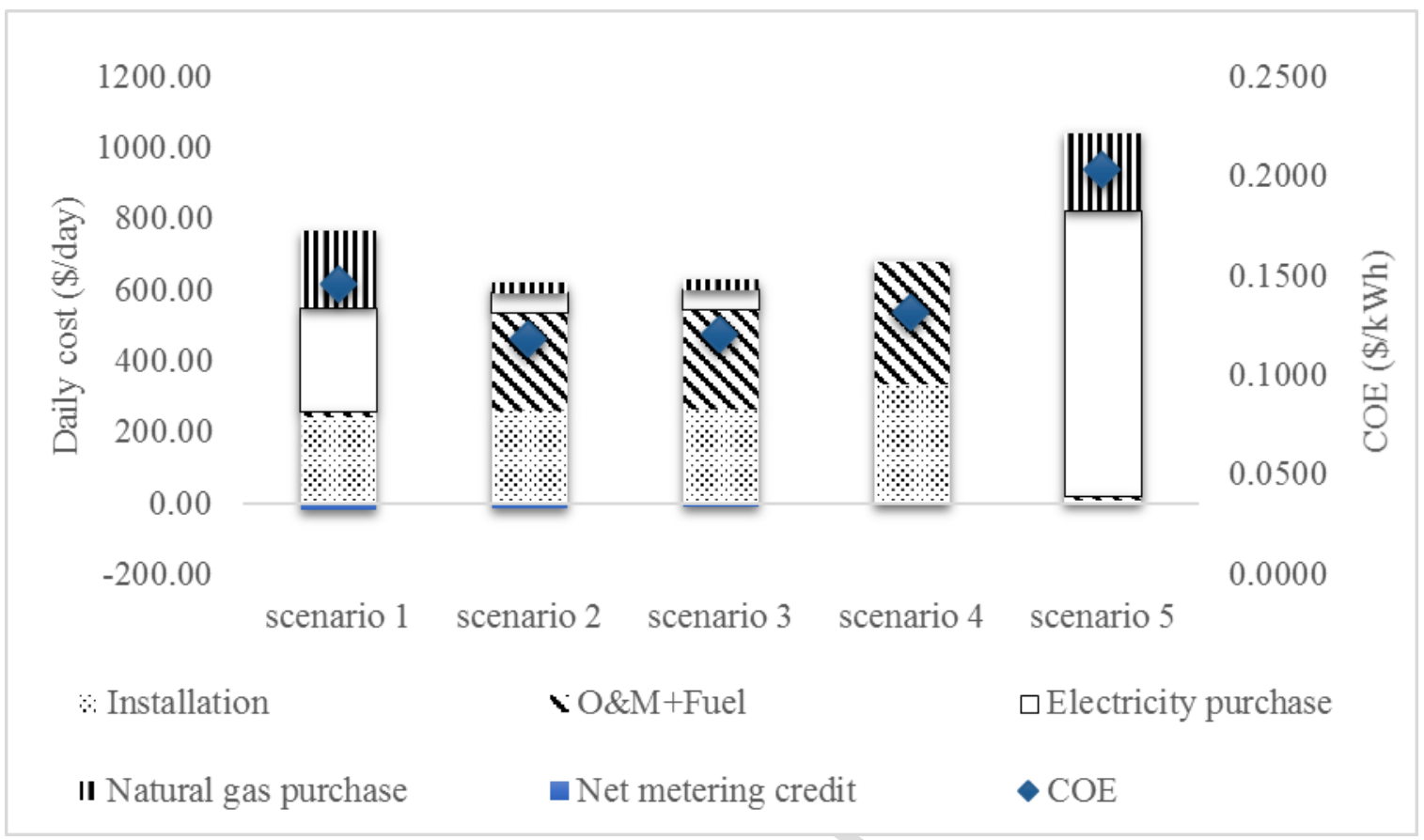

Fig. 9. COE values and cost composition for various scenarios.

To evaluate the effect of demand patterns from other times of the year on the optimal microgrid configuration, the model was also tested using daily electrical and thermal load data for summer. The lowest cost, $\$ 0.1136 / \mathrm{kWh}$, is also found for scenario 2 employing the $100 \mathrm{~kW}$ BCHP with solar PV and battery storage. Scenario 1, with a $170 \mathrm{~kW}$ wind turbine capacity and $130 \mathrm{~kW}$ of PV achieves a COE of $\$ 0.1349 / \mathrm{kWh}$, which is lower than the COE of scenario 1 in winter. That is because the heating demand is much lower in summer and the influence from the absence of a heat source in scenario 1 is minimized. For the same reason, the COE of scenario 4, with a $200 \mathrm{~kW}$ gasifier, is $\$ 0.1390 / \mathrm{kWh}$ in summer, which is higher compared to the COE in winter.

\subsubsection{Optimal microgrid dispatch}

Figs. 10-13 illustrate the optimal energy flows from the BCHP, WT, PV, and BT units as well as the grid to the demand during the selected 24 hour period. These graphs show the optimal dynamic operation based on the cost minimization.

For scenario 1, when no BCHP is adopted, most of the electricity during midnight to early morning is supplied by purchasing electricity from the utility due to the absence of PV generation and low wind speed $(<2.5 \mathrm{~m} / \mathrm{s})$ for the data set selected. The morning peak load demand occurs between 07:00 to 09:00 am coinciding with an increasing time of use tariff; therefore, the BT is used to balance the demand in conjunction with PV. From 10:00 am to 16:00 $\mathrm{pm}$, all of the electricity is generated from PV. After 07:00 pm, PV generation declines while as does the wind generation and import of grid power again increases to meet the nighttime demand (Fig.10).

Scenarios 2 and 3 show similar optimal operating schedules except for the addition of the $\mathrm{BCHP}$ that carries most of the demand not met by PV. Grid electricity is purchased after 20:00 
452 when both BT reserve is depleted, PV is absent and the residual demand exceeds the $100 \mathrm{~kW}$ supply from the BCHP unit (Figs. 11-12).

Scenario 4 considers the case of having an oversized BCHP $(200 \mathrm{~kW})$ in the microgrid. In this case the BCHP is large enough to meet virtually all the nighttime demand when lower cost PV generation is absent with the exception of a small contribution from the battery in the 458 later evening. No grid power is purchased and the microgrid independently meets the full system demand (Fig. 13).

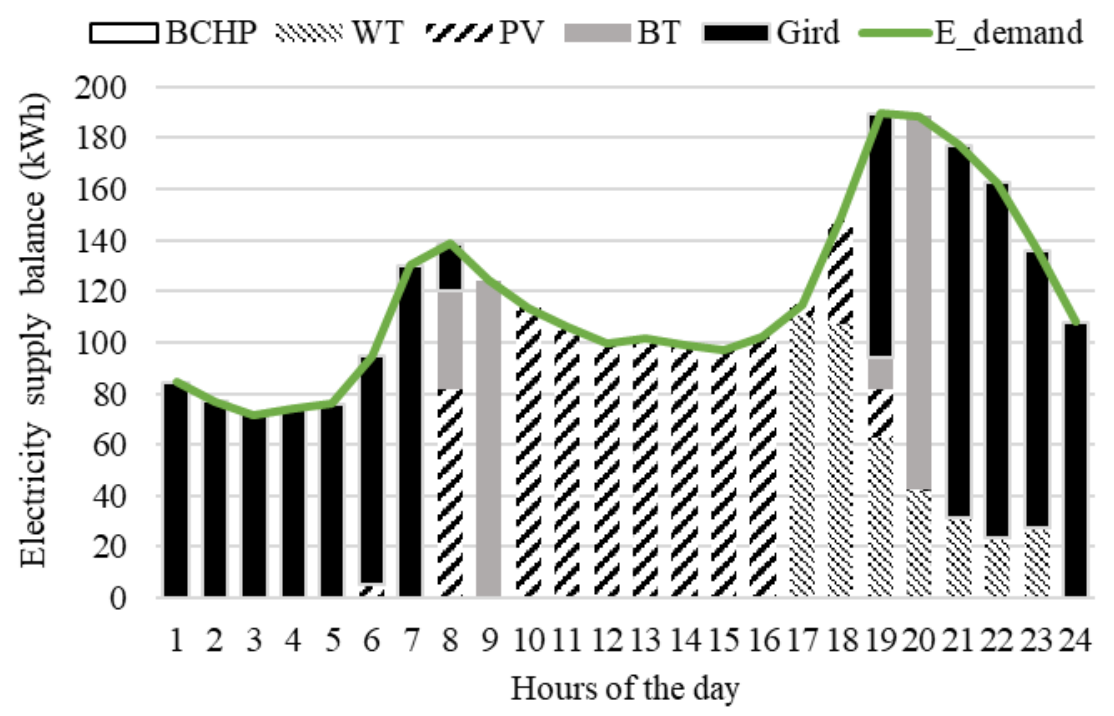

Fig. 10. Optimal electricity supply for scenario 1.

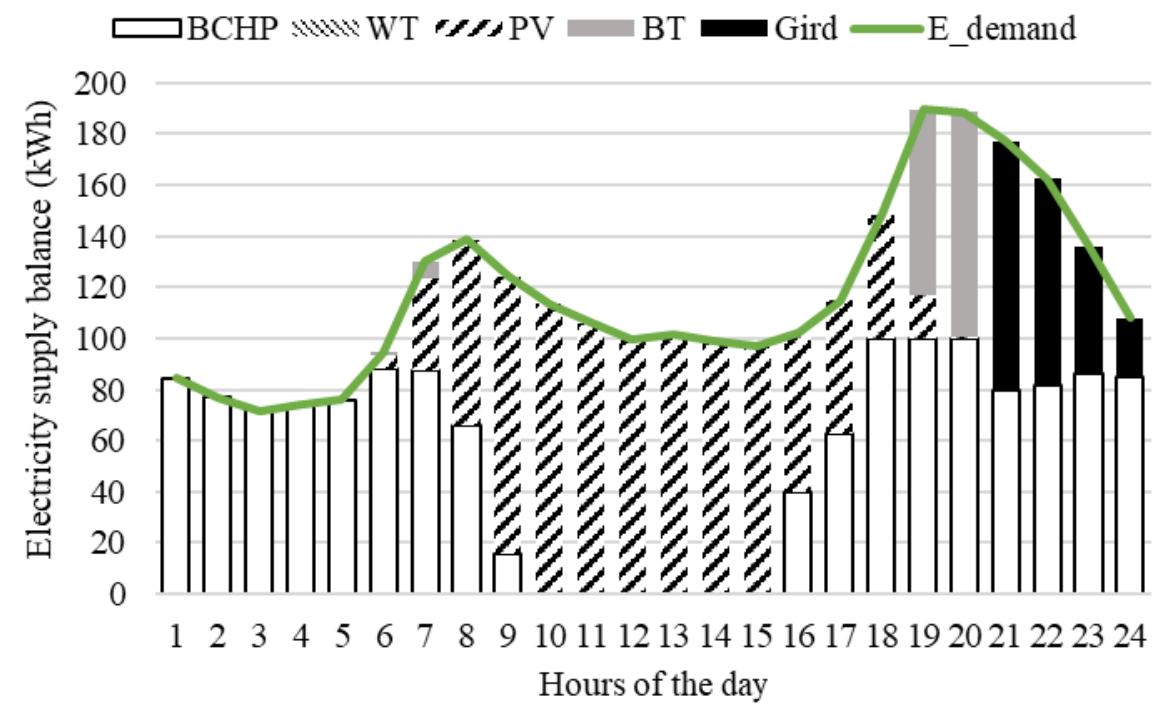

Fig. 11. Optimal electricity supply for scenario 2. 


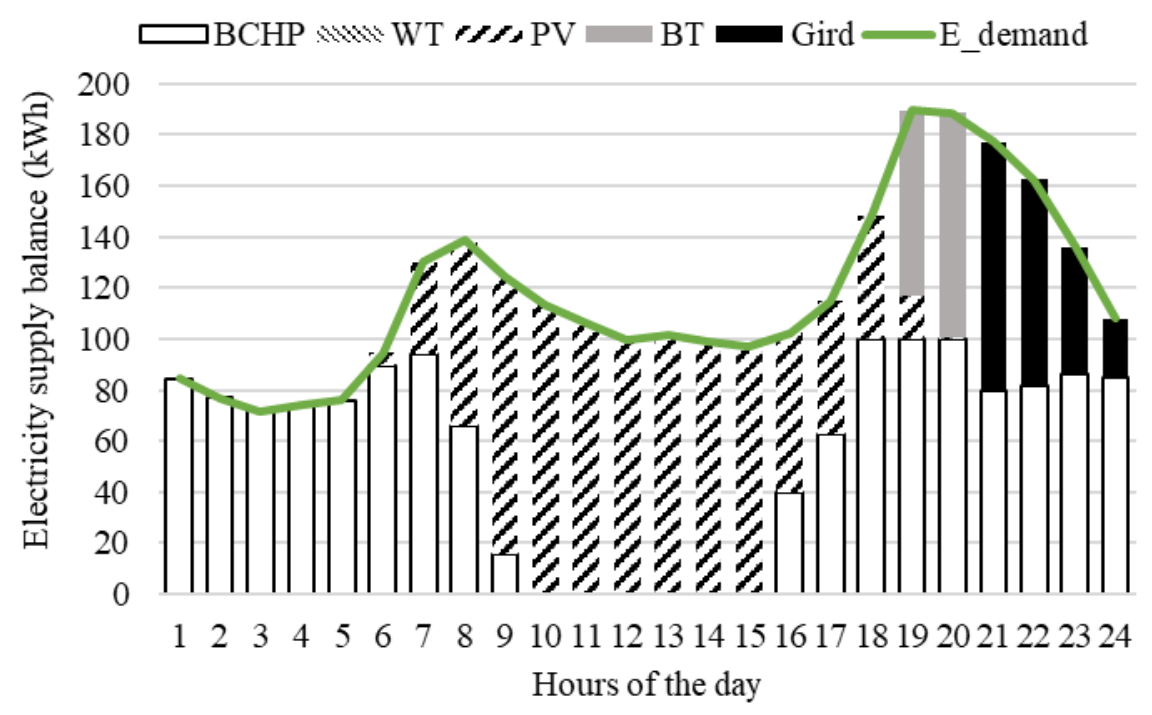

463

464

465

466

467

468

469

470

471

472

473

474

475

476
Fig. 12. Optimal electricity supply for scenario 3.

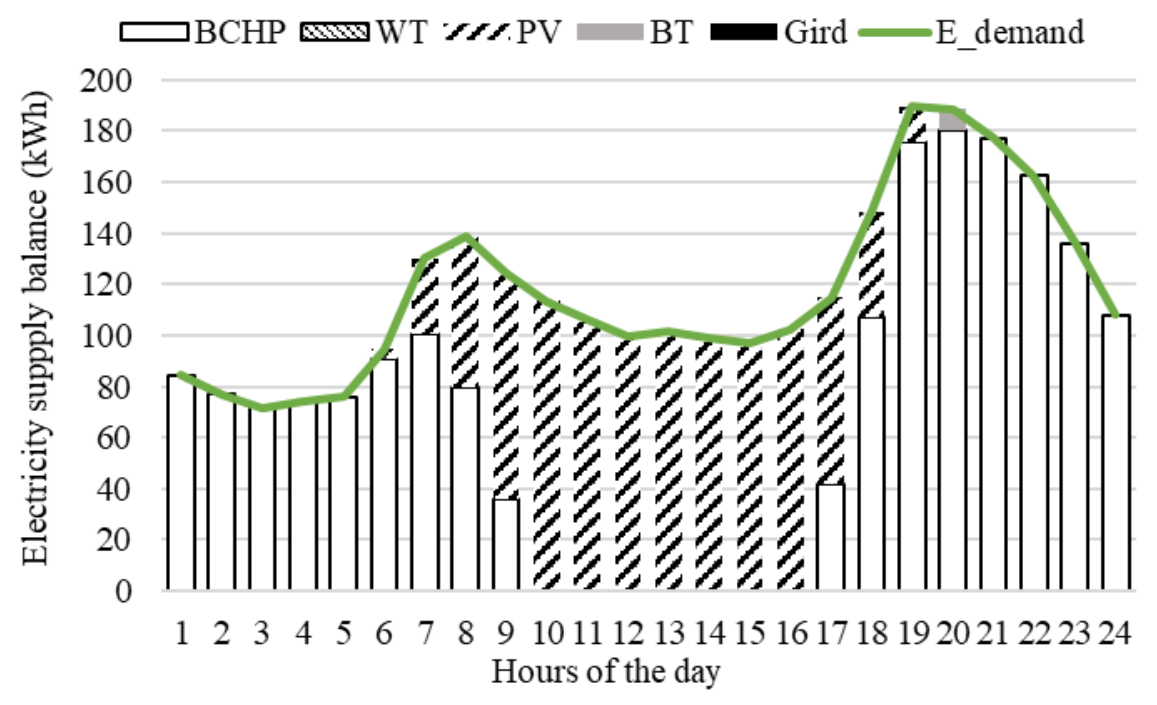

\subsection{Sensitivity analyses}

Fig. 13. Optimal electricity supply for scenario 4.

Sensitivity analyses were performed on BT capacity, electricity and natural gas prices, and energy demands. The analysis was based on the results obtained from the most optimistic WT and PV capacities giving the lowest cost.

\subsubsection{Effects of battery capacity}

To study the effect of battery capacity on the COE, the battery energy storage was varied from 0 to $300 \mathrm{kWh}$. The upper limit corresponds to the storage size of charging the battery with $100 \mathrm{kWh} / \mathrm{h}$ for $3 \mathrm{~h}$. Because the sliding time window width is $4 \mathrm{~h}$, the BT should be able to store at least $3 \mathrm{~h}$ of production. Fig. 14 illustrates $\mathrm{COE}$ as a function of the battery size for the 4 scenarios with the optimal capacity of WT and PV. For scenarios 1,2 and 3, the COE decreases 
as the storage size increases. The larger the storage, the less purchased electricity is required by the customer during the higher tariff period. At approximately $125 \mathrm{kWh}$, the COE begins to increase due to the limitation of the gasifier capacity. With increasing length of the prediction window, part of the storage capacity becomes redundant. For example, if with an $80 \mathrm{~kW}$ enginegenerator set and a 12 hours sliding time window, even if $100 \%$ of the model generation is stored over the first 11 hours, the optimal BT capacity will not be $880 \mathrm{kWh}$, but instead will be something less to still meet the demand over the model interval.

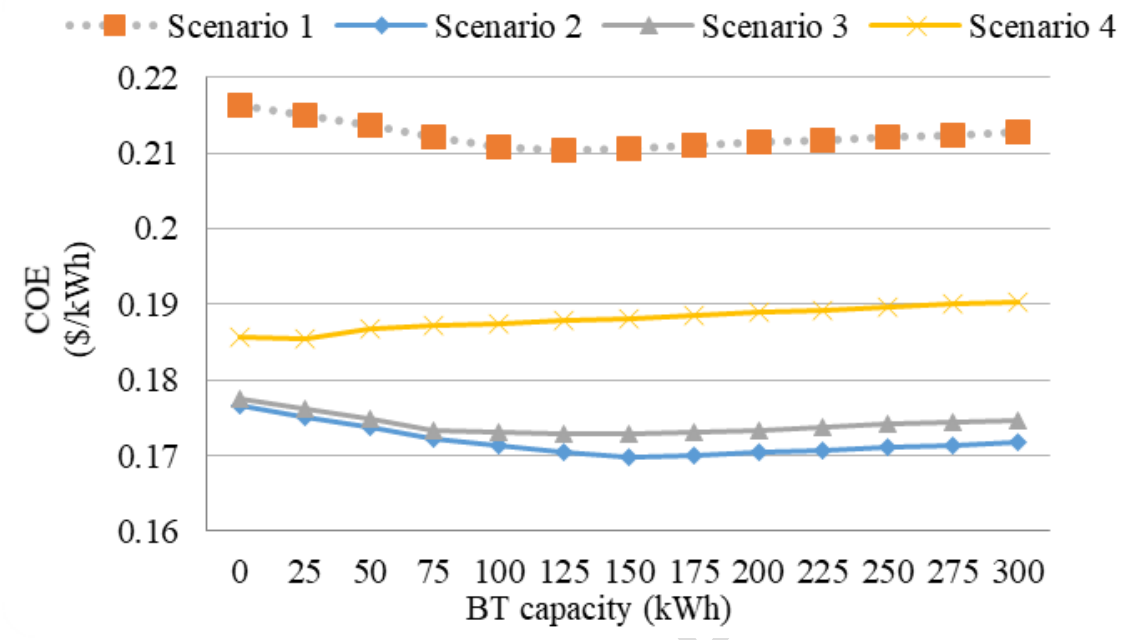

Fig. 14. COE as a function of battery capacity.

\subsubsection{Effects of electricity and natural gas price}

Fig. 15 and Fig. 16 show the results for the cost reduction ratio obtained by changing the electricity and natural gas price from $60 \%$ below to $60 \%$ above the reference prices. The microgrid provides greater cost savings as the price of purchased electricity increases (Fig. 15). However, the marginal benefit of having the microgrid declines with increasing grid price. A breakeven point is found for scenarios 1 and 4 at grid prices that are 55 and $45 \%$ lower than the assumed base case or reference price (negative cost reduction ratios indicate a preference for utility grid purchase). Moreover, although scenario 4 has the lowest cost savings at lower grid prices, as the grid price increases this scenario eventually achieves the same savings as scenarios 2 and 3 and breaks even with scenario 1 at a grid price about $20 \%$ lower than the reference price. If the electricity price is reduced more than $20 \%$, the no-BCHP case, scenario 1 , is preferred. As the purchased electricity price continues to increase, the larger BCHP capacity becomes more attractive.

For scenario 1, as natural gas price changes from $60 \%$ below to $60 \%$ above the reference price, the COE cost reduction ratio decreases from $32 \%$ to $25 \%$ due to the lack of heat recovery from a BCHP unit (Fig. 16). For scenarios 2, 3 and 4, the BCHP heat recovery and producer gas can almost meet the full heat demand, therefore, increasing natural gas price does not influence the COE reduction ratio and a nearly positive linear relationship develops over the remainder of the cost range. 


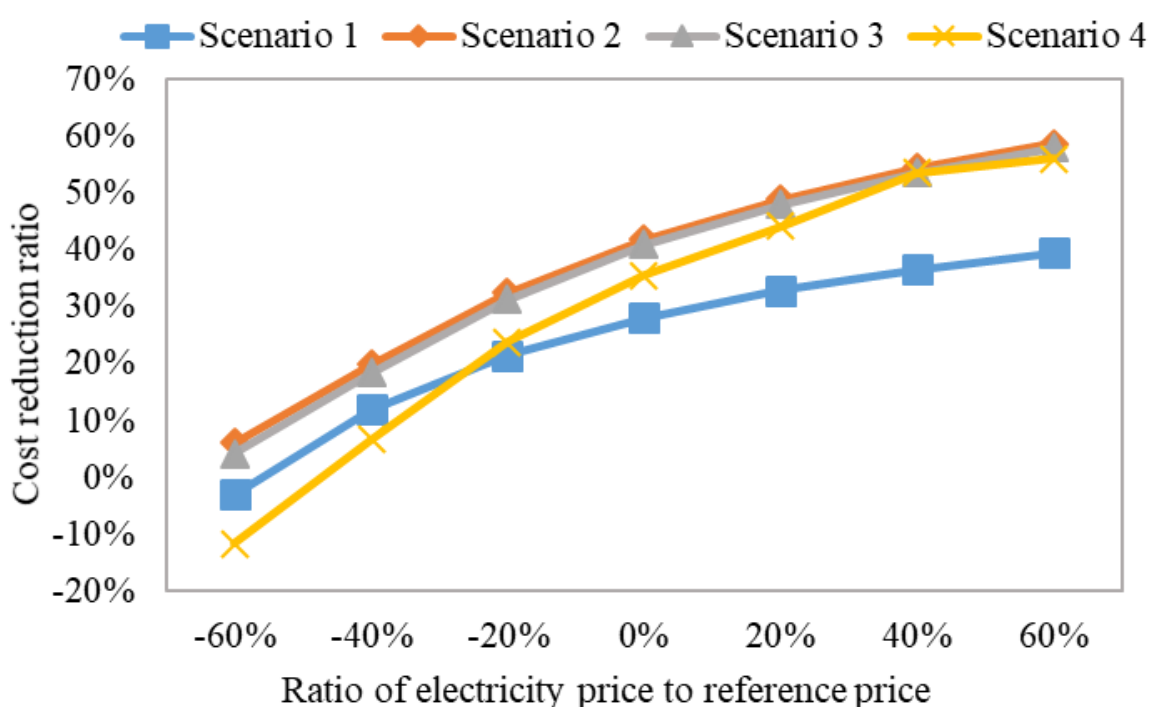

Fig. 15. COE reduction ratio as a function of increased electricity price.

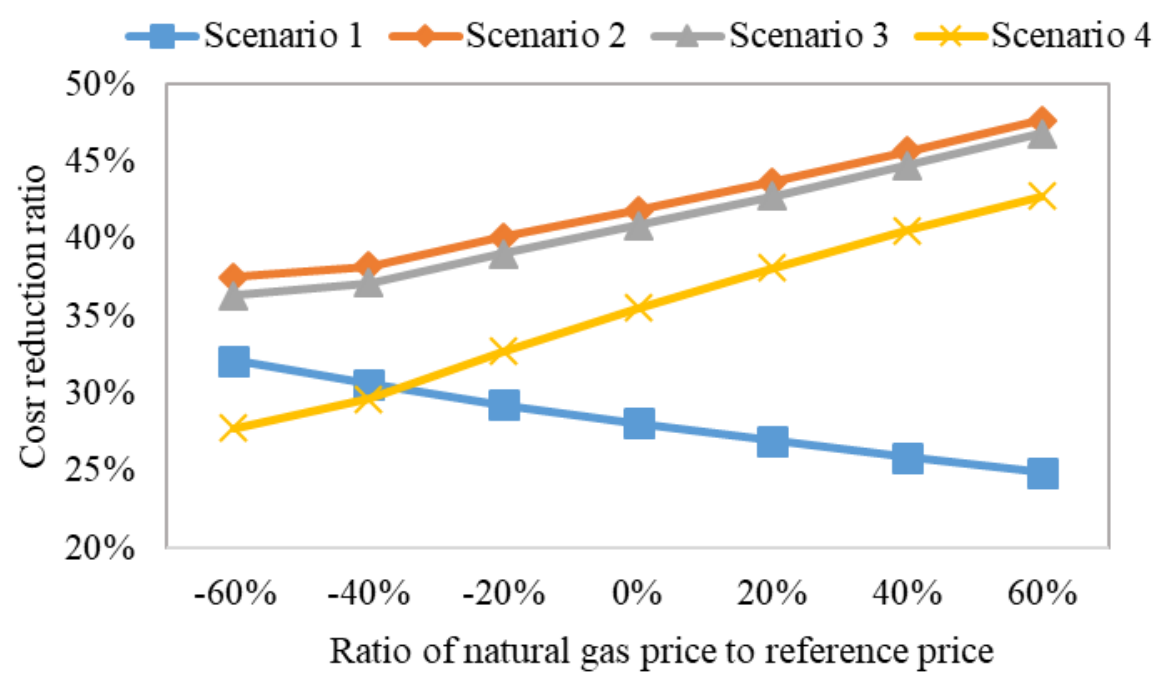

Fig. 16. COE reduction ratio as a function of increased natural gas price.

\subsubsection{Effects of demand changes}

Fig. 17 and Fig. 18 show the results for the cost reduction ratio obtained by changing the electricity and heat demand from $60 \%$ below to $60 \%$ above the reference values. The model 512 yields a maximum cost reduction at around a $20 \%$ increase in the base electricity demand. At this 513 demand level, the microgrid capacity is fully utilized for an overall improvement in cost of 514 generation (Fig. 17). For the case of no BCHP or only a single BCHP unit is installed, the cost 515 reduction ratio decreases slightly as the heat demand increases (Fig. 18). The overall impact on 516 the $\mathrm{COE}$ is minor for scenarios 2 and 3, however, because the only heat resource in the microgrid 517 is from BCHP (no electric resistance heating), which is absent in scenario 1, the COE becomes 518 more sensitive to heat demand. For scenario 4, with $200 \mathrm{~kW} \mathrm{BCHP} \mathrm{capacity,} \mathrm{even} \mathrm{when} \mathrm{the} \mathrm{heat}$ 519 demand is increased by $60 \%$ and the peak load is slightly over $200 \mathrm{~kW}$, the microgrid still 
supplies most of the thermal energy from engine heat recovery and the boiler. Therefore, increasing the heat demand does not require much additional natural gas and a positive relationship results in contrast to that for scenario 1 .

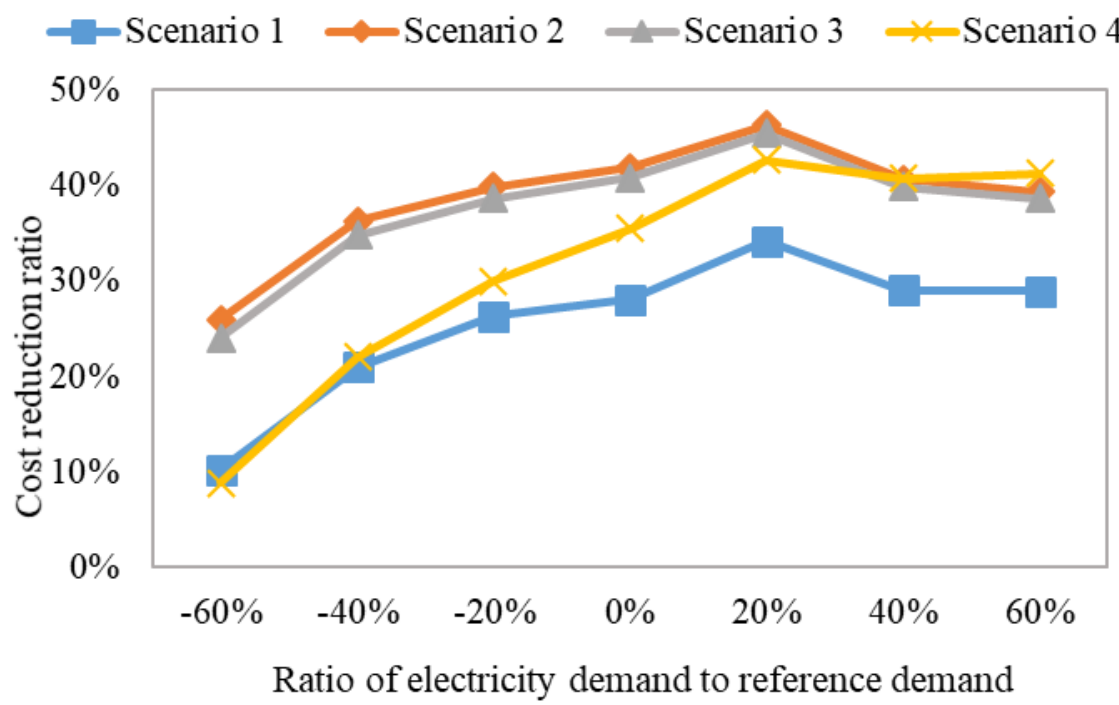

Fig. 17. COE reduction ratio as a function of increased electricity demand.

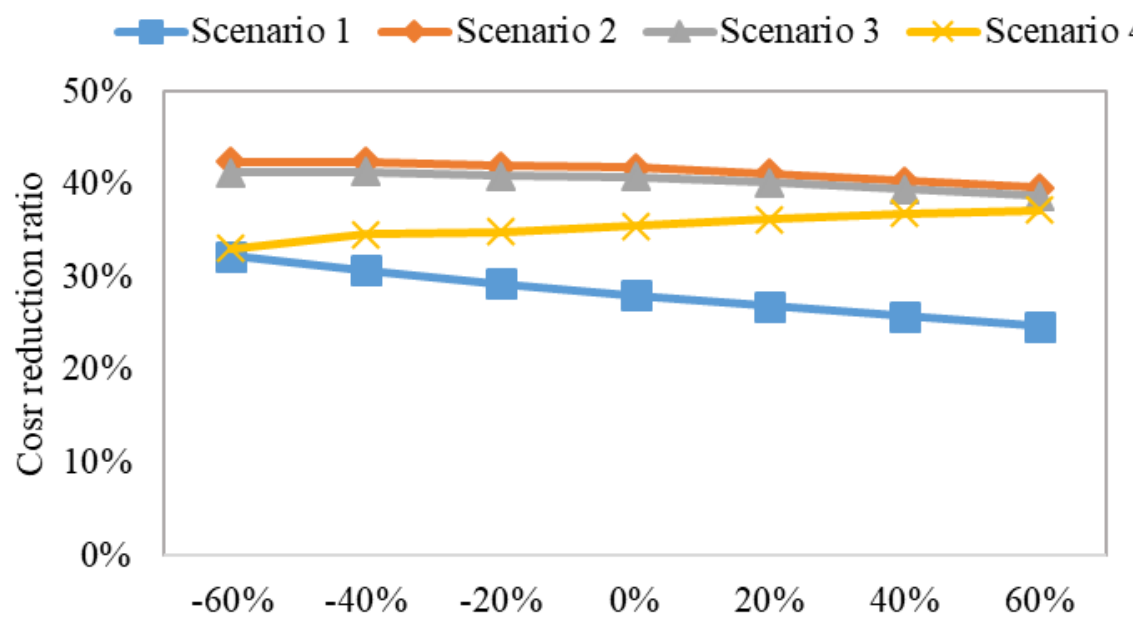

Ratio of heat demand to reference demand

Fig. 18. COE reduction ratio as a function of increased heat demand.

\subsection{Stochastic model results}

Many of the technical and economic assumptions used in the model are subject to uncertainty as well as variability. To assess the potential risk associated with decisions around a particular microgrid design, a stochastic model was developed employing Monte Carlo simulation for COE. Histograms from the Monte Carlo simulations are presented in Fig. 19. The 
The $200 \mathrm{~kW}$ BCHP case (scenario 4) shows the widest variation in COE with cost mostly ranging between 0.01 and $0.26 \$ / \mathrm{kWh}$, a width of $\$ 0.25 / \mathrm{kWh}$ while the scenario 2 and 3 span about $\$ 0.17 / \mathrm{kWh}$. The no BCHP case (scenario 1) shows the narrowest variation in COE around the mean of $\$ 0.13 / \mathrm{kWh}$.
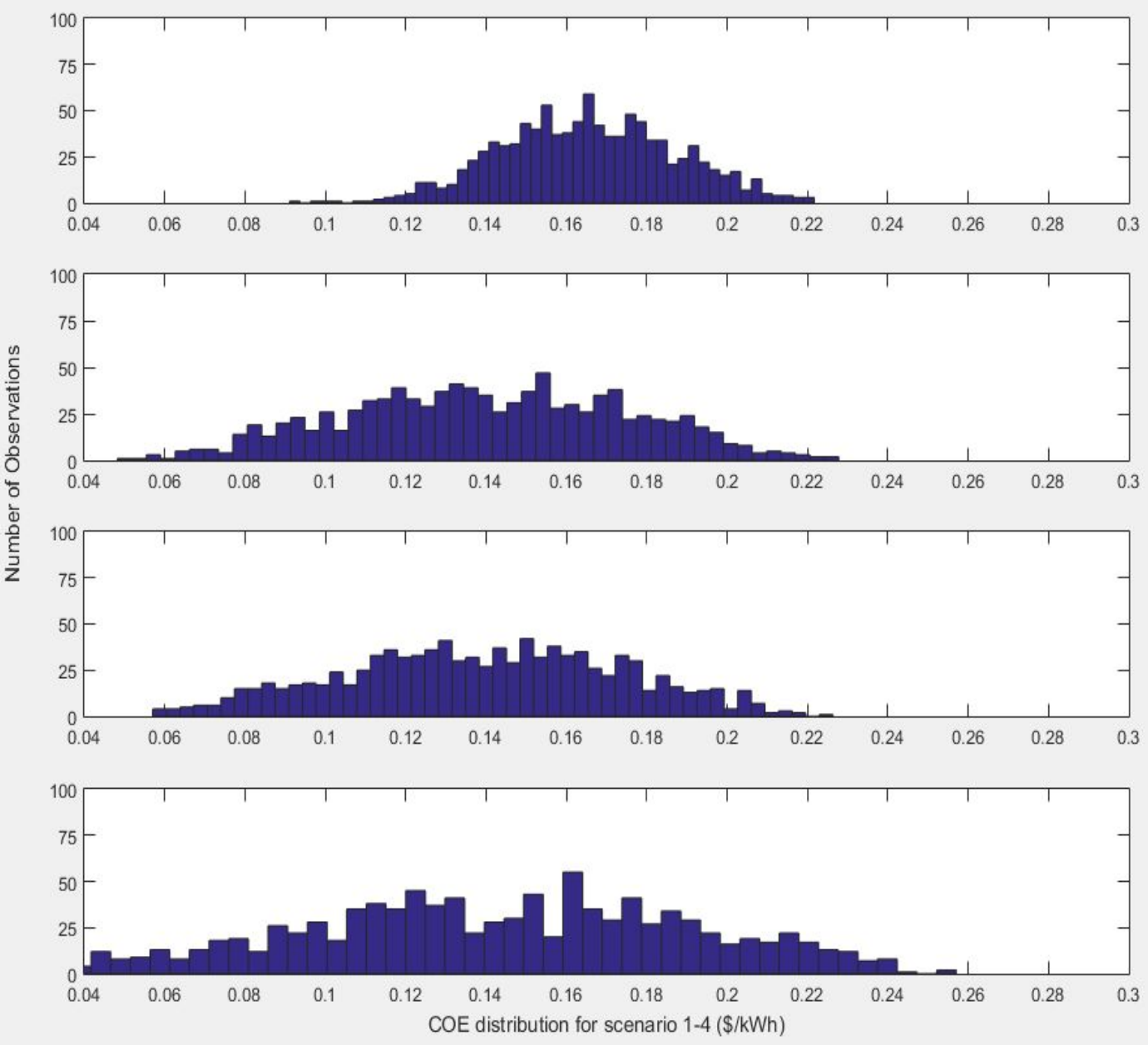

0

Table 8 shows statistics for these and other important results from the Monte Carlo simulations including descriptive statistics of the scenario distributions, the probabilities associated with any microgrid scenario reaching the optimal situation (deterministic COE), and the probability that any microgrid scenario will be preferred over the conventional utility grid supply (scenario 5). Note that scenario 4 has the highest probability, about $46 \%$, of reaching the optimal COE. There is a better than 28 and $31 \%$ chance that the COE of scenarios 2 and 3 are less than or equal to the optimal value. For scenario 1, the probability of achieving the optimal $\mathrm{COE}$ is only about $20 \%$, however, the distribution of $\mathrm{COE}$ is narrower around the mean. Even with uncertainty in the renewable generation, the microgrid options still yield odds of having lower COE than the utility supply only option (scenario 5) under the assumptions used. 
Table 8 COE results from MCS.

\begin{tabular}{lllllll}
\hline Scenario & \multicolumn{3}{l}{ COE values from MCS $(\$ / \mathrm{kWh})$} & $\mathrm{P}(\leq$ optimum COE $)$ & $\mathrm{P}(\leq \mathrm{COE}$ of Scenario 5) \\
\cline { 2 - 5 } & Min & Max & Mean & Range & & \\
\hline 1 & 0.0911 & 0.2217 & 0.1653 & 0.1306 & $19.80 \%$ & $96.00 \%$ \\
2 & 0.0482 & 0.2278 & 0.1402 & 0.1796 & $28.00 \%$ & $>99.9 \%$ \\
3 & 0.0570 & 0.2263 & 0.1391 & 0.1693 & $30.60 \%$ & $>99.9 \%$ \\
4 & 0.0123 & 0.2570 & 0.1427 & 0.2447 & $45.89 \%$ & $>99.9 \%$ \\
\hline
\end{tabular}

553

From the deterministic optimization analysis, scenario 2 has the lowest COE, nevertheless, if all the uncertainty factors are considered, scenario 3 provides the opportunity to achieve the lowest COE overall, albeit with reasonably low probability. With a 4-hour sliding time window, and the large BCHP capacity, any gasifier or engine failure in any but the first hour while the utility TOU electricity price is high, allows the BT and PGS storage to accommodate the lack of BCHP generation. For scenario 2, with the smaller $100 \mathrm{~kW}$ BCHP unit and no PGS, accommodation cannot be fully provided by the BT. Scenario 2 is also more dependent on solar energy than scenario 3 and 4, consequently, the uncertainty from solar radiation is reflected in the higher minimum cost for scenario 2 . Scenario 4 also shows a much wider range of possible outcomes. To illustrate, the expected COE from scenario 2 is lower than scenario 4, but the odds of achieving that cost are lower. The microgrid design should consider the odds of obtaining performance below expectations and understand the tolerable risk.

\subsection{Sensitivity analysis of stochastic variables}

Sensitivities of the results are presented for the three main power generation units, BCHP, WT and PV (Table 9). Changing the BCHP capital cost by $15 \%$ from the reference value results in average changes of 2.62, 2.00 and $9.87 \%$ in the mean COE for scenarios 2-4. When the BCHP O\&M cost was changed by $15 \%$, the average changes were $2.82,4.89$ and $6.96 \%$ in mean $\mathrm{COE}$ for these same scenarios 2-4. It is apparent that the BCHP investment and O\&M cost uncertainty is more sensitive in the COE of scenario 4. With respect to the O\&M cost, for each scenario, the COE varies by less than $5 \%$ indicating that COE is less sensitive to O\&M cost category, although BCHP O\&M cost is more sensitive than the WT and PV O\&M costs.

The variation in wind speed and solar radiation yield greater than 5\% change in the final cost for scenario 1, however, solar radiation does not show significant influence on the other scenarios. Therefore, in terms of total cost, the variation in market price is more important than 
Table 9 Sensitivity analysis of the MCS results.

\begin{tabular}{lllll}
\hline \multirow{2}{*}{ Case } & \multicolumn{5}{c}{ Mean COE increase/decrease vs. baseline } \\
\cline { 2 - 5 } & 1 & 2 & 3 & 4 \\
\hline$+15 \%$ BCHP Capital cost & - & $2.62 \%$ & $2.00 \%$ & $9.87 \%$ \\
$+15 \%$ WT Capital cost & $2.38 \%$ & - & - & - \\
$+15 \%$ PV Capital cost & $2.28 \%$ & $3.93 \%$ & $2.34 \%$ & $9.56 \%$ \\
$+15 \%$ BCHP O\&M cost & - & $2.82 \%$ & $4.89 \%$ & $6.96 \%$ \\
$+15 \%$ WT O\&M cost & $0.00 \%$ & - & - & - \\
$+15 \%$ PV O\&M cost & $0.63 \%$ & $-1.93 \%$ & $-0.07 \%$ & $0.92 \%$ \\
$+15 \%$ Wind speed & $-6.36 \%$ & - & - & - \\
$+15 \%$ Solar irradiance & $-7.03 \%$ & $-3.44 \%$ & $-0.36 \%$ & $3.06 \%$ \\
\hline
\end{tabular}

A sliding time window optimization modeling approach was applied to the optimal design and dispatch scheduling of a renewable microgrid supplying both heat and electricity. A model microgrid was evaluated with biomass combined heat and power, wind and solar electricity generation, gas-fired boiler, and battery electric, producer gas, and thermal energy storage included.

For the economic assumptions employed, BCHP can significantly improve the costefficiency of such a microgrid when compared with utility-supplied grid electricity and natural gas to meet the electrical and heat demands. While for the example location used the mean wind speed was low and wind generation was not selected as optimal, other locations may show superior wind performance. In the optimal scheduling, the inclusion of batteries allows storing electrical energy when utility time of use rates are low and electricity purchase is acceptable, and satisfying demand from storage when the utility rates are high.

608 Sensitivity analysis indicated a greater sensitivity to capital cost than the O\&M cost for the range 609 of assumptions evaluated. The model provides a means to determine the major risk factors in the 610 microgrid design and weigh the various advantages and disadvantages of each microgrid 611 configuration. Further work will compare optimized scenarios based on both short-term and 612 annual performance and include the uncertainties arising from demand-side management to alter 613 both electricity and heat demand in a combined optimization. 


\section{Acknowledgments}

Funding for this research was provided by the National Science Foundation through a Partnership for International Research and Education (PIRE) grant. We also gratefully acknowledge the financial support of the China Scholarship Council (CSC).

\section{Reference}

[1] Lasseter RH. Microgrids. Power Engineering Society Winter Meeting: IEEE; 2002, p. 305.

[2] Palensky P, Dietrich D. Demand side management: Demand response, intelligent energy systems, and smart loads. IEEE transactions on industrial informatics 2011;7:381.

[3] Hatziargyriou N, Asano H, Iravani R, Marnay C. Microgrids. IEEE Power and Energy 2007;5:78.

[4] Montuori L, Alcázar-Ortega M, Álvarez-Bel C, Domijan A. Integration of renewable energy in microgrids coordinated with demand response resources: Economic evaluation of a biomass gasification plant by Homer Simulator. Applied Energy 2014;132:15.

[5] Acakpovi A, Hagan EB, Michael MB. Cost Benefit Analysis of Self-Optimized Hybrid SolarWind-Hydro Electrical Energy Supply as compared to HOMER Optimization. International Journal of Computer Applications 2015;114.

[6] Mamaghani AH, Escandon SAA, Najafi B, Shirazi A, Rinaldi F. Techno-economic feasibility of photovoltaic, wind, diesel and hybrid electrification systems for off-grid rural electrification in Colombia. Renewable Energy 2016;97:293.

[7] Hafez O, Bhattacharya K. Optimal planning and design of a renewable energy based supply system for microgrids. Renewable Energy 2012;45:7.

[8] Castellanos JG, Walker M, Poggio D, Pourkashanian M, Nimmo W. Modelling an off-grid integrated renewable energy system for rural electrification in India using photovoltaics and anaerobic digestion. Renewable Energy 2015;74:390.

[9] Marnay C, Venkataramanan G, Stadler M, Siddiqui AS, Firestone R, Chandran B. Optimal technology selection and operation of commercial-building microgrids. IEEE Transactions on Power Systems 2008;23:975.

[10] Siddiqui AS, Marnay C, Edwards JL, Firestone R, Ghosh S, Stadler M. Effects of carbon tax on microgrid combined heat and power adoption. Journal of Energy Engineering 2005; 131:2.

[11] Stadler M, Siddiqui A, Marnay C, Aki H, Lai J. Control of greenhouse gas emissions by optimal DER technology investment and energy management in zero-net-energy buildings. European Transactions on Electrical Power 2011;21:1291.

[12] Sen R, Bhattacharyya SC. Off-grid electricity generation with renewable energy technologies in India: An application of HOMER. Renewable Energy 2014;62:388.

[13] Braslavsky JH, Wall JR, Reedman LJ. Optimal distributed energy resources and the cost of reduced greenhouse gas emissions in a large retail shopping centre. Applied Energy 2015;155:120.

[14] Hawkes A, Leach M. Modelling high level system design and unit commitment for a microgrid. Applied energy 2009;86:1253.

[15] Ren H, Gao W. A MILP model for integrated plan and evaluation of distributed energy systems. Applied Energy 2010;87:1001.

[16] Ren H, Zhou W, Nakagami Ki, Gao W, Wu Q. Multi-objective optimization for the operation of distributed energy systems considering economic and environmental aspects. Applied Energy 2010;87:3642.

[17] Kellogg W, Nehrir M, Venkataramanan G, Gerez V. Generation unit sizing and cost analysis for stand-alone wind, photovoltaic, and hybrid wind/PV systems. IEEE Transactions on energy conversion 1998;13:70.

[18] Zhang D, Shah N, Papageorgiou LG. Efficient energy consumption and operation management in a smart building with microgrid. Energy Conversion and Management 2013;74:209.

[19] Omu A, Choudhary R, Boies A. Distributed energy resource system optimisation using mixed integer linear programming. Energy Policy 2013;61:249. 
663

664

665

666

667

668

669

670

671

672

673

674

675

676

677

678

679

680

681

682

683

684

685

686

687

688

689

690

691

692

693

694

695

696

697

698

699

700

701

702

703

704

705

706

707

708

709

710

711

[20] Marzband M, Ghadimi M, Sumper A, Domínguez-García JL. Experimental validation of a realtime energy management system using multi-period gravitational search algorithm for microgrids in islanded mode. Applied Energy 2014;128:164.

[21] Nwulu NI, Xia X. Optimal dispatch for a microgrid incorporating renewables and demand response. Renewable Energy 2017;101:16.

[22] Zhang D, Evangelisti S, Lettieri P, Papageorgiou LG. Optimal design of CHP-based microgrids: Multiobjective optimisation and life cycle assessment. Energy 2015;85:181.

[23] Wang H, Yin W, Abdollahi E, Lahdelma R, Jiao W. Modelling and optimization of CHP based district heating system with renewable energy production and energy storage. Applied Energy 2015;159:401.

[24] Motevasel M, Seifi AR, Niknam T. Multi-objective energy management of CHP (combined heat and power)-based micro-grid. Energy 2013;51:123.

[25] Moradi MH, Hajinazari M, Jamasb S, Paripour M. An energy management system (EMS) strategy for combined heat and power (CHP) systems based on a hybrid optimization method employing fuzzy programming. Energy 2013;49:86.

[26] Brandoni C, Renzi M. Optimal sizing of hybrid solar micro-CHP systems for the household sector. Applied Thermal Engineering 2015;75:896.

[27] Basu AK, Bhattacharya A, Chowdhury S, Chowdhury S. Planned scheduling for economic power sharing in a CHP-based micro-grid. IEEE Transactions on power systems 2012;27:30.

[28] Basu A, Chowdhury S, Chowdhury S. Operational management of CHP-based microgrid. Power System Technology (POWERCON), 2010 International Conference on: IEEE; 2010, p. 1.

[29] Xu X, Jia H, Wang D, David CY, Chiang H-D. Hierarchical energy management system for multi-source multi-product microgrids. Renewable Energy 2015;78:621.

[30] Moradi MH, Eskandari M. A hybrid method for simultaneous optimization of DG capacity and operational strategy in microgrids considering uncertainty in electricity price forecasting. Renewable Energy 2014;68:697.

[31] Coelho VN, Coelho IM, Coelho BN, Cohen MW, Reis AJ, Silva SM, et al. Multi-objective energy storage power dispatching using plug-in vehicles in a smart-microgrid. Renewable Energy 2016;89:730.

[32] Haddadian H, Noroozian R. Optimal operation of active distribution systems based on microgrid structure. Renewable Energy 2017;104:197.

[33] Baziar A, Kavousi-Fard A. Considering uncertainty in the optimal energy management of renewable micro-grids including storage devices. Renewable Energy 2013;59:158.

[34] Abdullah MA, Muttaqi KM, Agalgaonkar AP. Sustainable energy system design with distributed renewable resources considering economic, environmental and uncertainty aspects. Renewable Energy 2015;78:165.

[35] Neves D, Brito MC, Silva CA. Impact of solar and wind forecast uncertainties on demand response of isolated microgrids. Renewable Energy 2016;87:1003.

[36] Yan X, Abbes D, Francois B. Uncertainty analysis for day ahead power reserve quantification in an urban microgrid including PV generators. Renewable Energy 2017;106:288.

[37] Samimi A, Nikzad M, Siano P. Scenario-based stochastic framework for coupled active and reactive power market in smart distribution systems with demand response programs. Renewable Energy 2017;109:22.

[38] Narayan A, Ponnambalam K. Risk-averse stochastic programming approach for microgrid planning under uncertainty. Renewable Energy 2017;101:399.

[39] Mandelli S, Merlo M, Colombo E. Novel procedure to formulate load profiles for off-grid rural areas. Energy for Sustainable Development 2016;31:130.

[40] Chaudry M, Wu J, Jenkins N. A sequential Monte Carlo model of the combined GB gas and electricity network. Energy Policy 2013;62:473. 
[41] Palma-Behnke R, Benavides C, Lanas F, Severino B, Reyes L, Llanos J, et al. A microgrid energy management system based on the rolling horizon strategy. IEEE Transactions on Smart Grid 2013;4:996.

[42] Marietta MP, Graells M, Guerrero JM. A rolling horizon rescheduling strategy for flexible energy in a microgrid. IEEE Energycon: IEEE; 2014, p. 1297.

[43] Fang T, Lahdelma R. Optimization of combined heat and power production with heat storage based on sliding time window method. Applied Energy 2016;162:723.

[44] Wang X, Palazoglu A, El-Farra NH. Operational optimization and demand response of hybrid renewable energy systems. Applied Energy 2015;143:324.

[45] Siqi C, JunYong L, Jiaqi Y, Yaqi N, Yue X, Xin Z, et al. Optimal coordinated operation for microgrid with hybrid energy storage and diesel generator. Power System Technology (POWERCON), 2014 International Conference on: IEEE; 2014, p. 3207.

[46] Pereira M, de la Peña DM, Limon D. Robust economic model predictive control of a community micro-grid. Renewable Energy 2017;100:3.

[47] Wang C, Liu Y, Li X, Guo L, Qiao L, Lu H. Energy management system for stand-alone dieselwind-biomass microgrid with energy storage system. Energy 2016;97:90.

[48] Jiang B, Fei Y. Smart home in smart microgrid: A cost-effective energy ecosystem with intelligent hierarchical agents. IEEE Transactions on Smart Grid 2015;6:3.

[49] Xie L, Ilic MD. Model predictive economic/environmental dispatch of power systems with intermittent resources. Power \& Energy Society General Meeting, 2009 PES'09 IEEE: IEEE; 2009, p. 1.

[50] Silvente J, Kopanos GM, Pistikopoulos EN, Espuña A. A rolling horizon optimization framework for the simultaneous energy supply and demand planning in microgrids. Applied Energy 2015;155:485.

[51] Berg BA, Billoire A. Markov chain monte carlo simulations: Wiley Online Library; 2008.

[52] Bashir M, Sadeh J. Optimal sizing of hybrid wind/photovoltaic/battery considering the uncertainty of wind and photovoltaic power using Monte Carlo. Environment and Electrical Engineering (EEEIC), 2012 11th International Conference on: IEEE; 2012, p. 1081.

[53] Reddy SS. Optimal scheduling of thermal-wind-solar power system with storage. Renewable Energy 2017;101:1357.

[54] Dufo-López R, Cristóbal-Monreal IR, Yusta JM. Stochastic-heuristic methodology for the optimisation of components and control variables of PV-wind-diesel-battery stand-alone systems. Renewable Energy 2016;99:919.

[55] Jahangir H, Ahmadian A, Golkar MA. Optimal design of stand-alone microgrid resources based on proposed Monte-Carlo simulation. Innovative Smart Grid Technologies-Asia: IEEE; 2015, p. 1. [56] Jenkins BM, Baxter LL, Koppejan J. Biomass combustion. Thermochemical processing of biomass: conversion into fuels, chemicals and power; 2011, p. 13.

[57] Jenkins B, Baxter L, Miles T. Combustion properties of biomass. Fuel processing technology 1998;54:17.

[58] Nguyen DT, Le LB. Optimal energy management for cooperative microgrids with renewable energy resources. Smart Grid Communications (SmartGridComm), 2013 IEEE International Conference on: IEEE; 2013, p. 678.

[59] Talari S, Yazdaninejad M, Haghifam M-R. Stochastic-based scheduling of the microgrid operation including wind turbines, photovoltaic cells, energy storages and responsive loads. IET Generation, Transmission \& Distribution 2015;9:1498.

[60] Brum M, Erickson P, Jenkins B, Kornbluth K. A comparative study of district and individual energy systems providing electrical-based heating, cooling, and domestic hot water to a low-energy use residential community. Energy and Buildings 2015;92:306.

[61] Jenkins BM. A comment on the optimal sizing of a biomass utilization facility under constant and variable cost scaling. Biomass and Bioenergy 1997;13:1.

[62] Silvente J, Aguirre A, Crexells G, Zamarripa M, Méndez C, Graells M, et al. Hybrid time representation for the scheduling of energy supply and demand in smart grids. Comput Aided Chem Eng 2013;32:553. 
763 [63] Wickwire S. Biomass Combined Heat and Power catalog of technologies. Washington, DC $764 \quad 2007 ; 1: 10$.

765 [64] DiOrio N, Dobos A, Janzou S. Economic Analysis Case Studies of Battery Energy Storage with 766 SAM. National Renewable Energy Lab.(NREL), Golden, CO; 2015.

767 [65] Tidball R, Bluestein J, Rodriguez N, Knoke S. Cost and performance assumptions for modeling 768 electricity generation technologies. ICF International, Fairfax, VA; 2010, p. 275.

769 [66] Energy Metering (NEM) Available: http://www.cpuc.ca.gov/General.aspx?id=3800Net $770 \quad$ [Accessed: October 2016]. 
- A model was developed to optimize the design of a biomass-integrated renewable energy microgrid employing combined heat and power with energy storage.

- A receding horizon optimization with Monte Carlo simulation was proposed to evaluate optimal microgrid design and dispatch under uncertainty.

- The model application provides a means to determine major risk factors associated with alternative design integration and operating strategies. 